NBER WORKING PAPER SERIES

WHEAT OR STRAWBERRIES? INTERMEDIATED TRADE WITH LIMITED CONTRACTING.

\author{
Kala Krishna \\ Lena Sheveleva \\ Working Paper 20630 \\ http://www.nber.org/papers/w20630 \\ NATIONAL BUREAU OF ECONOMIC RESEARCH \\ 1050 Massachusetts Avenue \\ Cambridge, MA 02138 \\ October 2014
}

We are grateful to Manolis Galenianos, Nageeb Ali, and Yu Awaya for their comments on an earlier draft, and to Corinne Jones for research assistance. We are also grateful to participants at the 2012 Conference on Economic Growth and Development at the Indian Statistical Institute, Delhi, for comments. The views expressed herein are those of the authors and do not necessarily reflect the views of the National Bureau of Economic Research.

NBER working papers are circulated for discussion and comment purposes. They have not been peerreviewed or been subject to the review by the NBER Board of Directors that accompanies official NBER publications.

(C) 2014 by Kala Krishna and Lena Sheveleva. All rights reserved. Short sections of text, not to exceed two paragraphs, may be quoted without explicit permission provided that full credit, including $₫$ notice, is given to the source. 
Wheat or Strawberries? Intermediated Trade with Limited Contracting.

Kala Krishna and Lena Sheveleva

NBER Working Paper No. 20630

October 2014, Revised January 2016

JEL No. O12

\begin{abstract}
Why do developing countries fail to specialize in products in which they appear to have a comparative advantage? We propose a model of agricultural trade with intermediation that explains how hold-up resulting from poor contracting environments can produce such an outcome. We use the model to explore the role of production subsidies, support prices, easing sanitary and phyto-sanitary (SPS) requirements, and the creation of local markets in resolving the hold-up problem. The model highlights the importance of infrastructure in aligning production with comparative advantage and sheds light on the pass-through of the world price to the producer.
\end{abstract}

Kala Krishna

Department of Economics

523 Kern Graduate Building

The Pennsylvania State University

University Park, PA 16802

and NBER

kmk4@psu.edu

Lena Sheveleva

Cardiff Business School

Aberconway Building

Colum Dr, Cardiff CF10 3EU

United Kingdom

yas0306@gmail.com

A data appendix is available at http://www.nber.org/data-appendix/w20630 


\title{
Wheat or Strawberries? Intermediated Trade with Limited Contracting. *
}

\author{
Kala Krishna \\ The Pennsylvania State University, CES-Ifo and NBER \\ Lena Sheveleva \\ Cardiff University \\ January 17, 2016
}

\begin{abstract}
Why do developing countries fail to specialize in products in which they appear to have a comparative advantage? We propose a model of agricultural trade with intermediation that explains how hold-up resulting from poor contracting environments can produce such an outcome. We use the model to explore the role of production subsidies, support prices, easing sanitary and phyto-sanitary (SPS) requirements, and the creation of local markets in resolving the hold-up problem. The model highlights the importance of infrastructure in aligning production with comparative advantage and sheds light on the pass-through of the world price to the producer.
\end{abstract}

There is a large literature which documents that labor productivity in developing countries is lower than in developed ones, and that this is more so in agriculture than in manufacturing. For example, Caselli (2005) shows that aggregate productivity for countries at the $90^{\text {th }}$ percentile of income relative to the countries at the $10^{\text {th }}$ percentile is 22 , while this ratio for agriculture is 451 Lagakos and Waugh (2013) show that for staples such as maize,

*Krishna: Kern Graduate Building, Room 523, The Pennsylvania State University, University Park, PA, 16802, USA, (e-mail:kmk4@psu.edu). Sheveleva: Cardiff Business School, T43, Aberconway Building, Colum Drive, Cardiff, CF10 3EU, UK(e-mail: yas0306@gmail.com).We are grateful to Manolis Galenianos, Nageeb Ali, and Yu Awaya for their comments on an earlier draft, and to Corinne Jones for research assistance. We are also grateful to participants at the 2012 Conference on Economic Growth and Development at the Indian Statistical Institute, Delhi, for comments

${ }^{1}$ Such differences in agricultural productivity could arise from differences in efficiencies conditional on the set of products made and/or composition effects. 
rice, and wheat the ratio is 146, 90, and 83 respectively, twice as high as for agriculture overall. Yet farmers in developing countries persist in producing staples like wheat, corn or maize, rather than exotic fruits and vegetables that are highly valued in urban areas or export markets.

We explain why this could occur using a model of agricultural trade with intermediation and a lack of contract enforcement. Comparative advantage alone is far from sufficient for the efficient pattern of specialization to take hold. Challenges associated with exporting agricultural produce range from difficulties in transport and storage of perishables, to difficulties in meeting sanitary and phyto-sanitary requirements (SPS). All of these exacerbate the problems associated with the poor contracting environments endemic in less developed economies.

Using our model we identify the conditions ensuring that in the presence of intermediation agricultural producers make production decisions according to comparative advantage. We explore policies that can align production choices with comparative advantage. Local markets for perishable agricultural products, price guarantees, production subsidies as well as infrastructure improvements that reduce transport costs are shown to help align comparative advantage and production.

The environment in a developing country is very different from that in a developed one. A number of factors limit the farmer's ability to transport his strawberries to an urban or export location by himself: roads are poor, trucks are expensive, and credit markets are poorly developed. Hence a farmer must rely on intermediaries (traders) to access markets. At the same time, traders are scarce, irregular in their arrivals, and unreliable in their promises as contracts are poorly enforced. Though improvements in the contracting environment can alleviate the challenges of farm-gate trade in a developing country, the required judicial and political reforms to do this are difficult and time consuming to implement. We therefore take as given the problematic contracting environment in less developed countries, and build a simple model that captures essential features of such an environment.

In our setup, farmers have the technology to produce staples, which we call wheat, and an exotic perishable produce, which we call strawberries. These goods differ along four dimensions: the farmer's ability to consume them, the farmer's efficiency in producing them, the kind of market in which they are traded, and the degree of perishability. The first good, wheat, is a storable staple that a farmer can subsist on, and/or which is sold in a competitive market. The second, strawberries, is a perishable non-staple which is traded only through intermediaries. Farmers can survive on their wheat if the need arises, while they cannot survive on strawberries. Not only are strawberries nutritionally inadequate, but they are perishable, and have to be sold quickly. This gives intermediaries bargaining power 
when markets are thin, and makes farmers reluctant to grow strawberries, which makes intermediaries reluctant to enter, resulting in the expected thin markets materializing.

Traders, unlike farmers, have access to a competitive market for strawberries. Entry into intermediation is free and traders incur a sunk cost at entry. Farmers and traders cannot contract on price ex-ante and traders arrive at the farm-gate randomly. The trader who offers the highest price to the farmer gets strawberries. If there is no trader at the farmer's door step, he exercises his outside option. The farmers' outside option could be selling to a local canning factory, or could be 0 if no such option is available..$^{2}$

We solve the model and characterize all the possible equilibria as a function of the four primitive parameters: the farmers' productivity in strawberries, the world price of strawberries, the farmers' outside option (reservation price), and the sunk costs of intermediation. Of particular interest is the region in parameter space with multiple equilibria where the hold-up problem occurs.

The hold-up occurs because traders cannot credibly promise a worthwhile price to farmers if they make strawberries. Ex-post, a trader who is the sole buyer has no incentive to pay the farmer more than his outside option. Anticipating this, the farmer chooses not to produce strawberries unless he believes that a sufficient number of traders enter to ensure competition among traders. However, were more farmers to produce strawberries, more traders would enter and this would make the production of strawberries profitable. So depending on farmer's and traders beliefs about one another actions, and the primitive parameters, two equilibria could occur. In the "good" equilibrium farmers specialize in strawberries, which they have a comparative advantage in, and there is intermediation. In the "bad" equilibrium, there is no intermediation and the staple is produced.

Analysis of the model suggests that even if the government is not able to resolve the core issue, namely the underlying lack of enforceable contracts, there are policies that ensure specialization according to comparative advantage. An export board that provides farmers with an outside option or a production subsidy for strawberries eliminate the "bad" equilibrium, with the production subsidy being a more efficient policy than the export board. Agricultural extension programs and easing of SPS restrictions can also eliminate the "bad" equilibria.

Local markets, where farmers can sell strawberries under competitive conditions, provide an endogenous outside option. The price of strawberries in the local market depends on their world price less traders' cost of accessing it. To access these markets farmers incur a cost too. The price of strawberries at the local market and the farmer's cost of accessing it pin down his outside option at the farm-gate. Hence a sufficient fall in the cost of accessing the

\footnotetext{
${ }^{2}$ Outcomes are unaffected by whether we assume the trader knows how many competitors he faces, or not, as explained below.
} 
local market removes the "bad" equilibrium. Similarly, agricultural extensions and easing of the SPS requirements raise the farmer's pay-off at the local market and can also eliminate the "bad" equilibria.

Farmers near cities and trading centers are likely to have access to local markets with a high price for strawberries. In remote locations, on the other hand, farm-gate trade is likely to be prevalent. Moreover, as farmers in thin markets fear the power of intermediaries, they may choose not to produce strawberries without local markets that provide enough of an outside option. This suggests that farmers in remote locations where local markets are hard to access are less likely to grow strawberries.

Furthermore, the extent of pass-through of the world price into the producer price depends on access to a local market. With local markets, the level of intermediation is independent of export price fluctuations, and the farm-gate price adjusts one for one in response to world price changes. In contrast, when farmers have limited access to world markets directly, the level of intermediation itself adjusts so that pass through to the farmer is far from complete.

In the rest of the introduction we discuss the modelling assumptions we make, provide anecdotal evidence in support of the model and relate it to the wider literature.

\subsection{Motivating the Modelling Assumptions}

The model we present in subsequent sections focuses on some essential aspects of agricultural trade in order to retain tractability. In this section we turn to the existing empirical literature and case studies to explain our modelling choices.

Intermediaries have been known to play an important role in facilitating agricultural trade in general and in developing countries in particular. Fafchamps, Gabre-Madhin and Minten (2005) describe the environment in which agricultural farmers and traders interact in Africa. They document that there are a large number of small intermediaries who specialize in buying from producers and selling to wholesale traders or exporters. In our model we focus on these small itinerant traders.

Fafchamps and Hill (2005) document that farmers face a decision whether to sell at the farm gate or to travel to the nearest organized market to sell the good. Farmers are less likely to travel to the local market and more likely to sell to the itinerant trader when the nearest market is far or the cost of transportation is high. Similarly, Osborne (2005) finds that in poorer and more remote areas, traders have more market power than in markets that are located to big trading centers. Consistent with their findings, in our model, farmers in remote areas sell at the farm-gate at lower prices than farmers close to ports. 
A number of historical examples of the hold-up issue that we focus on in the paper have been documented. One such account can be found in Kranton and Swamy (2008). They argue that the Opium Agency, initiated by the East India Company (EIC) in India, had a similar problem and recognized it. As the agency was the sole procurer of opium it had monopsony power, its agents had incentives to behave opportunistically towards farmers. Such behavior would have resulted in farmers switching to other crops. In order to prevent this the Opium Agency expended significant resources monitoring their own agents.

The role that cooperatives played in establishing the dairy industry in India, e.g., the Amul cooperative, is another historical account that supports our model. In India prior to "Operation Flood,"milk was hard to come by in urban areas. Farmers were reluctant to produce milk because of the risk of spoilage and the lack of distribution channels. Dairy cooperatives that took hold in India during "Operation Flood" encouraged production by giving farmers a "fair" price for their milk. The success of the cooperatives was a key part of the "white revolution" when India went from being a milk deficient nation in the 1970s to being the world's largest milk producer in 2011$]^{3}$

An important feature of our work is that we do not allow for the possibility of repeated interactions between farmers and traders. This is justified by the extent of uncertainty that prevails in developing countries. Weather variability, political uncertainty and disease, all of which make people focus on the short term so that the future is highly discounted. Such considerations call for the use of static models that exclude repeated interactions and relational contracting.

The long term relations and reputational concerns have received a lot of attention in recent years and have been shown to play an important role in facilitating contracts. Banerjee and Duflo (2000) focus on the role played by repeated interactions in the software industry in India. Macchiavello and Morjaria (2012) focus on the role of repeated interactions in the context of rose exports from Kenya, while McMillan and Woodruff (1999) look at credit relations between firms in Vietnam. Antras and Foley (2011) show that prepayment for orders is more common when relational capital is low, i.e., at the start of a relationship. Greif (2005) uses historical examples to study how contractual problems were resolved among Magrabi traders. All these are established markets. Here, as in Kranton and Swamy (2008), we assume there are no relational contracts possible. Our focus is on why certain markets do not come into being when there is no repeated interaction, rather than on the operation of established markets.

\footnotetext{
${ }^{3}$ See Delgado, Narrod and Tiongco (2003) for more on how the white revolution occurred in India.
} 


\subsection{Relation to Existing Work}

Our work fits into recent literature on the effect of productivity and trade costs on patterns of specialization, see Costinot, Donaldson and Smith (2012), Costinot and Donaldson (2012), Sotelo (2013). However, all of this work abstracts from intermediation and the related frictions that arise. In contrast, we focus on precisely such frictions and explore their interaction with trade costs in defining (often suboptimal) patterns of specialization.

Our work is related to Antras and Costinot (1993) who introduce intermediation into a two-good two-country Ricardian framework to analyze the implications of globalization. They focus on the welfare effects of integration in the goods market versus intermediary markets, and, in contrast to us, assume that contracts are fully enforced and hold-up is not possible.

Our model highlights how intermediation in the absence of contracts can lead to a hold-up problem and multiple equilibria. Other papers that have emphasized multiplicity of equilibria and explored how policy intervention can be welfare improving include the big push and unbalanced growth type of stories as in Nurkse (1966), Rosenstein-Rodan (1943), Murphy, Shleifer and Vishny (1989), and Hirschman (1988). Unlike this literature, we focus on the contracting imperfections which result in the coordination failures that make farmers choose to produce low priced staples, despite seemingly more lucrative options being available.

Hausmann and Rodrik (2003) and Hausmann, Hwang and Rodrik (2007) portray development as a process of self discovery. Our model does not rely on the lack of self-knowledge to explain the shortage of investment in non traditional products. With contractual frictions farmers know about their options but choose not to avail of them because non traditional product markets are thin and holdup is likely.

Our paper is also related to a literature that focuses on price transmission in agricultural trade. Fafchamps and Hill (2008) analyze transmission of the export coffee price to the Uganda farmer who sells at the farm-gate. They find evidence of incomplete pass-through from the international price to farm-gate prices. They argue that the cause of this incomplete pass-through is the lack of information about world price movements on the part of the farmer ${ }^{4}$ Our model has no informational frictions and predicts that pass-through is incomplete in remote locations where farmers have no alternatives to farm-gate trade. When farmers have the option to sell at a local market where price depends on the export price, the pass-through of the world price into the farm-gate price is complete.

A good deal of attention has been paid recently to the role of infrastructure in facilitating market access and encouraging development. Casaburi, Glennerster and Suri (2013) provide

\footnotetext{
${ }^{4}$ In addition, Mitra et al. (2013) use an experimental framework to look at the role of information on prices.
} 
evidence that rural road reduce search costs and encourage intermediation. Using a regression discontinuity framework, they show that the price of the local crop, i.e., rice, falls with the construction of rural roads. This occurs due to competition from more efficient producers outside the region. Since in our model the intermediated good is not consumed locally, road improvements effectively reduce the cost of getting the export good to the market and increase producer price whether at the farm-gate or the local market.

We proceed as follows. Section 1 lays out the model. Section 2 constructs the equilibrium when farmers are risk neutral and examines its welfare properties. Section 3 incorporates a local market where farmers can sell their produce into the model. This is in addition to matching with a trader at the farm-gate. Section 4 explores various implications of the model as well as policies to alleviate existing distortions. Section 5 concludes.

\section{The Model}

The modelling framework builds on Burdett and Mortensen (1998) and Galenianos and Kircher (2008). The economy consists of a continuum of farmers of measure one and a continuum of traders whose measure $\theta$ is determined endogenously in equilibrium. Farmers can produce a staple or a perishable good. One unit of labour produces one unit of the staple and $\alpha$ units of the perishable good. Each farmer is endowed with one unit of labour. Farmers can either consume the staple or sell it at a fixed price which is normalized to unity.

The perishable good is traded in the competitive world market to which farmers have no access without intermediaries. The trader buys the good from the farmer at price $p$ and sells it to the exporter with the objective of maximizing his expected profit $\pi^{T}(p)$. There are an infinite number of potential traders who can become actual traders by paying a sunk entry cost $\kappa_{F}$. Each trader who pays the sunk cost randomly meets a single farmer, and with probability $P_{k}$ he meets $k$ competitors at the farm-gate. The farmer will sell his strawberries to the trader offering the highest price.

The farmer chooses how much of his one unit of labour to allocate to the production of the intermediated good $l \in[0,1]$, and how much to the production of the subsistence good $1-l$, to maximize his profit, $\pi^{F}$. He produces strawberries if he expects a sufficient number of intermediaries to enter, making producing it more profitable than producing wheat. The equilibrium that we will characterize consists of three objects: $l, \theta, F(p)$, where $F(p)$ is the distribution of prices that traders offer upon entry into intermediation. All agents take the strategies of all other traders and farmers as given, and choose their strategies simultaneously. The strategies are played and the outcomes are revealed. Since all farmers and traders are ex-ante identical and of measure zero, their individual actions do not affect the equilibrium 
outcome.

We assume that the trader decides on the price offer to the farmer before he observes the number of competitors. Alternatively, one could assume that price offers are made after seeing the number of competitors. In fact, the expected price at the farm-gate as well as trader profits are identical under the two assumptions, see Krishna (2009). Thus, the equilibrium outcomes, such as the level of intermediation and the production decisions of farmers are also the same in two scenarios. The key difference between the two assumptions is that the latter produces a more realistic distribution of prices. When traders make the price offer before observing the exact number of competitors a continuous distribution of farm-gate prices with the upper bound of the support below the world price arises, which is consistent with the documented price variations, e.g., see Fafchamps and Hill (2008).

Furthermore, the usual inefficiency in such models also exists here: a farmer may have no traders matched with him or a trader may lose out to a competitor. Such events involve waste relative to the operation of frictionless markets.

We begin by assuming that farmers and traders are risk neutral. This causes farmers to specialize in either the export or the staple good. Adding risk aversion on the side of the farmers moves the economy away from the corner solution ${ }^{5}$

\subsection{The Meeting Process}

We assume that farmers and traders meet according to a Poisson process. This process arises naturally when traders arbitrarily meet one out of $N$ farmers producing for export, and is convenient in modeling coordination frictions that result when there are many small market participants.

Then, $P_{k}$, the probability that a trader who randomly arrives at a farm-gate meets $k$ rivals can be derived as follows. Let $\lambda=\frac{1}{N}$ be the probability that a given trader visits this farmer. Then, if $T$ and $N$ go to infinity while their ratio is equal to $\theta$, i.e., $\theta=\frac{T}{N}$,

$$
P_{k}=\left(\begin{array}{c}
T-1 \\
k
\end{array}\right) \lambda^{k}(1-\lambda)^{T-1-k}=\frac{\theta^{k}}{k !} e^{-\theta} .
$$

It can be shown that the probability that $k$ traders arrive at a farmer's gate $Q_{k}$ is identical to $P_{k}$, the probability that a trader at the farm-gate meets $k$ rivals.

\footnotetext{
${ }^{5}$ We incorporate risk aversion in an Appendix available on request.
} 


\subsection{The Trader's problem}

The trader's problem consists of two parts. For a given level of market intermediation, $\theta$, a potential trader needs to decide whether to enter the intermediation market or not. Upon entry he has to decide what price to offer to the farmer he visits. As usual, we need to solve this backwards. First, consider the problem of optimally choosing the price to post given the distribution of prices of all other traders.

Let $p$ be the price that the trader offers to the farmer. The most important piece of information for the trader is the distribution of prices that other traders offer, $F(p){ }^{6}$ For an arbitrary $p$, the probability that a given trader makes the highest bid in a meeting with $k$ rivals is given by $[F(p)]^{k}$. The unconditional probability that a trader offering price $p$ is the highest bidder involves summing over the number of rivals the trader could potentially meet and is given by

$$
\sum_{k=0}^{\infty} P_{k}[F(p)]^{k}=\sum_{k=0}^{\infty} e^{-\theta} \frac{\theta^{k}}{k !}[F(p)]^{k}=e^{-\theta(1-F(p))}
$$

When $\alpha l^{*}$ is the equilibrium output of the intermediated good the trader who wins offering price $p$ makes $\left(P^{w}-p\right) \alpha l^{*}$. Thus, the expected profit of a trader offering price $p$ is

$$
\pi^{T}(p)=\left(P^{w}-p\right) \alpha l^{*} e^{-\theta(1-F(p))} .
$$

Let $R$ be the farmer's reservation price, i.e., the farmer's outside option. As mentioned earlier it could be a price offered by a local canning factory, or it could be 0 if no such option is available. Let

$$
p_{\max }=P^{w}\left(1-e^{-\theta}\right)+R e^{-\theta} .
$$

The following proposition summarizes the properties of the equilibrium:

Proposition 1. In the unique equilibrium, traders mix over the interval $\left[R, p^{\text {max }}\right]$ according to $F(p)$, where

$$
F(p)=\left\{\begin{array}{l}
0 \text { for } p<R \\
\frac{1}{\theta} \ln \left(\frac{P^{w}-R}{P^{w}-p}\right) \text { for } R \leq p \leq p^{\text {max }}
\end{array},\right.
$$

The traders' expected profits equal $\left(P^{w}-R\right) \alpha l^{*} e^{-\theta}$.

\footnotetext{
${ }^{6}$ This distribution could arise because each trader charges a different price or each plays a mixed strategy. How it arises is irrelevant.

${ }^{7}$ If $p$ is a random draw from $F(p)$, then the distribution of the maximum of the $k$ random draws, i.e., $\left\{p_{i}\right\}_{i=1}^{k}$, is given by $[F(p)]^{k}$.
} 
The proof that the distribution is continuous with a compact support on $\left[R, p_{\max }\right]$ is standard and is relegated to the appendix. Note that if $F(p)$ is an equilibrium distribution, for any price $p$ in it's the support the distribution the trader expected profits must be the same. Evaluated at $R$, trader profits are

$$
\pi^{T}(R)=\left(P^{w}-R\right) \alpha l^{*} e^{-\theta}=\bar{\pi}^{T}
$$

so that for all $p$ in the support of $F(p)$ :

$$
\pi^{T}(p)=\left(P^{w}-p\right) \alpha l^{*} e^{-\theta(1-F(p))}=\bar{\pi}^{T}
$$

This gives $F(p)$ uniquely, see Burdett and Judd (1983). Each trader could charge one price, with different traders choosing different prices so that $F(p)$ emerges, or each trader could be mixing over prices according to $F(p)$. 8

The upper bound of the support $p^{\max }$ is a convex combination $]^{9}$ of the world price and the farmer's reservation price. As the level of intermediation increases, $p_{\text {max }}$ increases, but as $e^{-\theta}<1$ for any value of $\theta, p_{\max }$ remains below $P^{w}$. The farmer's reservation price, $R$ binds the value of $p_{\max }$ from below. Trader expected profits given in equation (5) are increasing in $P^{w}$, and decreasing in $R$ and $\theta$.

Note that these are exactly the profits of a trader, competing a la Bertrand, who sets his price after knowing the number of competitors he faces at the farm-gate. If he has no competitors at the farm-gate, he offers the farmer $R$, and makes profits of $\left(P^{w}-R\right) \alpha l^{*}$. This event occurs with probability $e^{-\theta}$. Otherwise, competition forces him to raise his price to $P^{w}$ and he makes zero profits.

Now that we can evaluate the traders' expected profits prior to entry, we can consider their entry decision.

Proposition 2. The free entry level of intermediation is

$$
\theta=\left\{\begin{array}{l}
\ln \left(\frac{(P w-R) \alpha l^{*}}{\kappa_{F}}\right) \quad \text { if } \quad l^{*} \geq l_{\min } \\
0 \text { if } l^{*}<l_{\min }
\end{array}\right.
$$

where

$$
l_{\min }=\frac{\kappa_{F}}{\alpha\left(P^{w}-R\right)} .
$$

\footnotetext{
${ }^{8}$ All that matters to a trader is the probability that his price is the lowest and not the particular price distributions other firms use which is irrelevant both to the traders best response and to welfare.

${ }^{9}$ To see this note that: $e^{\theta}=1+\theta+\frac{\theta^{2}}{2 !}+\frac{\theta^{3}}{3 !} \ldots>1$ for any $\theta>0$ and thus, $0<e^{-\theta}<1$.
} 
Proof. Entry of traders will continue until:

$$
\pi^{T}(p)=\kappa_{F} .
$$

Since profits are the same at every point in the support, we can solve for the level of intermediation by equating profits at the lower end of the support, $R$, to the cost of entry, $\kappa_{F}:$

$$
\left(P^{w}-R\right) \alpha l^{*} e^{-\theta}=\kappa_{F} .
$$

Solving for $\theta$ gives

$$
\theta=\ln \left(\frac{\left(P^{w}-R\right) \alpha l^{*}}{\kappa_{F}}\right) .
$$

Thus, the equilibrium level of intermediation is increasing in the world price and the output of the export good. It is decreasing in the sunk cost and the farmer's reservation price. Note that $\theta>0$ if and only if

$$
\ln \left(\frac{\left(P^{w}-R\right) \alpha l^{*}}{\kappa_{F}}\right)>0
$$

or

$$
l^{*}>l_{\min }=\frac{\kappa_{F}}{\alpha\left(P^{w}-R\right)} .
$$

Proposition 2 means that positive levels of intermediation prevail when the output of the export good, $\alpha l^{*}$, exceeds a minimum level, denoted by $\alpha l_{\min }=\frac{\kappa_{F}}{\left(P^{w}-R\right)}$. In other words, if $l^{*}>l_{\min }$, intermediation occurs. The equilibrium level of intermediation rises with increases in the world price and decreases in the farmers' reservation price or the cost of intermediation.

\subsection{The Farmer's Problem}

We now describe the problem of a risk neutral farmer. Let $G_{k}(p)=[F(p)]^{k}$ be the cumulative density function of the highest price offered when the farmer meets $k$ traders. Each farmer has a linear utility function defined over the units of the staple good. A farmer who allocates $l$ units of labor to the intermediated good and $1-l$ units to the staple earns a profit

$$
\pi^{F}(l, p)=(\alpha p-1) l+1,
$$

when he receives a price $p$ from a trader for the intermediated good. Since the farmer is risk neutral he maximizes expected profits, and since he only consumes the numeraire good, his indirect utility is the same as his income. 
Let $E(p)$ be the price farmers expect to obtain for the export good at the arm-gate. If $\alpha E(p)-1>0$, the farmer will produce only the export good. When evaluating the expected price, farmers take the level of intermediation $\theta$, the pricing strategy of traders $F(\cdot)$, and the meeting process $\left\{Q_{k}\right\}_{k=0}^{\infty}$ as given. $Q_{k}$ has been defined earlier as the probability that $k$ traders arrive at a farmer's gate.

Lemma 3. Given the level of intermediation, $\theta$, the expected price at the farm-gate is given by

$$
\begin{aligned}
E(p) & =\sum_{k=0}^{\infty} Q_{k} \int_{R}^{p_{\max }} p d G_{k}(p) \\
& =P^{w}\left(1-e^{-\theta}(1+\theta)\right)+\operatorname{Re}^{-\theta}(1+\theta) .
\end{aligned}
$$

As $0<e^{-\theta}(1+\theta)<1$, the expected price is a convex combination of the world price $P^{w}$ and the farmer's reservation price $R .10$

The direct proof is in the Appendix.

A useful intuition for the expression of the expected price comes from the observation that in the first-price auction, the expected price is the same whether bids are made before or after the number of competitors has been observed as discussed above. If at most one intermediary shows up at the farm-gate, the farmer gets $R$. This happens with probability $e^{-\theta}(1+\theta)$. If more than one intermediary shows up at the farm-gate the price is bid up to $P^{w}$, which happens with probability $1-e^{-\theta}(1+\theta)$. Hence the expression in equation 10 .

The expected producer price increases with the world price $P^{w}$, and productivity of the export good $\alpha$, and decreases with the cost of farm-gate intermediation $\kappa_{F}$. Changes in $\alpha$ and $\kappa_{F}$ operate via $\theta$ : a higher $\alpha$ and lower $\kappa_{F}$ increase $\theta$, raising the weight on $P^{W}$. A higher $P^{w}$ affects the expected price both directly, and through raising the level of intermediation.

A higher value of $R$, on one hand, increases the farmer's outside option and therefore the expected farm-gate price. On the other hand, it decreases the level of intermediation, which pushes the expected farm-gate price down. The direct effect of an increase in $R$ dominates and the expected price rises:

$$
\frac{\partial E(p \mid \theta(l=1))}{\partial R}=e^{-\theta}>0
$$

A risk neutral farmer allocates labor between production of the export good and the staple depending on which is more profitable. Hence, the farmers' labor supply as a function of the expected price is given by

\footnotetext{
${ }^{10} e^{\theta}>1+\theta$ so $\frac{1}{1+\theta}>e^{-\theta}$ or $1>e^{-\theta}(1+\theta)$.
} 


$$
l(E(p))=\left\{\begin{array}{l}
1 \text { if } \alpha E(p)>1 \\
{[0,1] \text { if } \alpha E(p)=1} \\
0 \text { if } \alpha E(p)<1
\end{array}\right.
$$

Note that if $\alpha R \geq 1$ so is $\alpha E(p)$, and farmers specialize in the export good even if no intermediaries enter, i.e., $\theta=0$. When $\alpha R<1$ whether farmers specialize in the export good depends on the prevailing level of intermediation. Define $\theta_{\min }$ as the minimum level of intermediation necessary to induce farmers to produce the export good. An increase in $\theta$ raises the expected price as it reduces the weight on $R$. As $\theta$ rises and $E(p)$ exceeds $\frac{1}{\alpha}$, farmers specialize in the production of the export good and $l()=$.1 . We can write the farmers' choice of labor as the best response function to the prevailing level of intermediation:

$$
l(\theta)=\left\{\begin{array}{l}
1 \text { when } \alpha R \geq 1 \\
1 \text { for } \theta>\theta_{\min } \\
{[0,1] \text { if } \theta=\theta_{\min } \quad \text { when } \alpha R<1} \\
0 \text { for } \theta<\theta_{\min } .
\end{array}\right.
$$

Formally, $\theta_{\min }$ is the solution to $\alpha E(p)=1$. It is easy to see that $\theta_{\min }$ does not depend on $\kappa_{F}$ and decreases as $\alpha, P^{w}$ or $R$ rise.

\subsection{Equilibrium}

We first discuss the possible equilibrium configurations in terms of the traders and farmers best response functions. We then describe the relationship between the primitive parameters and the equilibrium configurations that they imply.

In equilibrium, each farmer chooses what to produce, and each active trader chooses what price to offer, so as to maximize their respective profits. All potential traders are indifferent between becoming active or not, and the decisions of these agents are mutually consistent.

The equilibrium consisting of three objects: $\theta, F(p), l(\theta)$, is pinned down by equations (12), (6), and (3). Depending on the values of the primitive parameters there are four possible equilibrium configurations, all depicted in Figures $1 \mathrm{a}, 1 \mathrm{~d}$. Figures $1 \mathrm{a}$ and $1 \mathrm{~b}$ show the equilibrium outcomes when $R<1 / \alpha$ and farmers specialize in the staple unless there is enough intermediation. In Figures $1 \mathrm{c}$ and $1 \mathrm{~d}, R>1 / \alpha$, so that farmers will produce the intermediated good regardless of the intermediation level.

In Figure 1a there is a unique equilibrium with complete specialization in the staple good. $\theta_{\min }>\theta(1)$ so that the best response functions $l(\theta)$ and $\theta(l)$ have only one intersection at the origin. Even if all farmers make only strawberries, intermediation is not profitable. This 
occurs when $P^{w}$ and $\alpha$ are low (e.g., agriculture is inefficient) and/or $\kappa_{F}$, the cost of entry for traders, is high.

Figure $1 \mathrm{~b}$ depicts multiple equilibria. The farmers best response function, $l(\theta)$, and traders' free entry condition, $\theta(l)$, intersect three times implying three equilibria. There are two complete specialization equilibria where farmers produce either strawberries or the staple, and an equilibrium where farmers are indifferent between producing ether one of the two goods. When intermediaries enter, $\alpha E(P)>1$, all farmers produce strawberries. If intermediaries do not enter all farmers produce the staple. When $\theta=\theta_{\min }$ and $\alpha E(P)=1$ farmers are indifferent between making either wheat or strawberries. This last equilibrium is unstable: small perturbations will move the economy to one of the two stable equilibria. For this reason in the rest of the paper we focus on the two specialization equilibria. 11

When $R>\frac{1}{\alpha}$, it is profitable to make strawberries even if there are no intermediaries so $l \equiv 1$. Figure $1 \mathrm{c}$ depicts the situation where the level of intermediation is positive. Figure 1d depicts the case where intermediaries do not enter, and the intermediated good is sold locally at a fixed price $R$. This case occurs if intermediation is inherently unprofitable, i.e., when the profit margin of a trader who offers $R$ and makes $\left(P^{w}-R\right) \alpha$ falls short of the intermediation cost $\kappa_{F}$, or

$$
\left(P^{w}-R\right) \alpha<\kappa_{F} .
$$

This occurs when $R$ and/or $\kappa_{F}$ is high or $\alpha$ and/or $P^{w}$ are low.

Next we outline the conditions on the primitive parameters that give rise to each of the equilibrium types. Figure 2 depicts the possible equilibrium outcomes for different values of the primitive parameters $R$ and $\kappa_{F}$ given $\alpha$ and $P^{w}$.

When $R<\frac{1}{\alpha}$ and $\kappa_{F}$ is relatively low, whether farmers produce the export good or not depends on their beliefs about the prevailing level of intermediation. In this case, multiple equilibria in the sense of Figure $1 \mathrm{~b}$ are endemic. In Figure 2 we call this region $M$. When $\kappa_{F}$ becomes so high that farmers find it unprofitable to enter, none of the export good will be made. In Figure 2 this region is labeled $W$ for wheat production, which corresponds to the situation in Figure 1a. The boundary between region $M$ and $W$ is defined by the condition $E(p \mid \theta)=\frac{1}{\alpha}$ as this is when farmers are indifferent between making the staple or the export

\footnotetext{
${ }^{11}$ While we limit the discussion of the unstable equilibrium it is worth noting that this equilibrium may involve pure or mixed strategies on the part of the farmer. To see this, note that trader profits are linear in $l$, so the fee entry level of intermediation depends on the average output of the export good per farmer. Let $\hat{l}$ be the average level of output of strawberries per farmer such that $\theta(\hat{l})=\theta_{\min }$, shown in Figure $1 \mathrm{~b}$. It is easy to see that whether all farmers produce $l=\hat{l}$, or a fraction farmers $\hat{l}$ make strawberries and the rest make wheat both imply the average output per farmer $\hat{l}$. More generally, whatever is the output of the individual farmer, as long as the average output per farmer is $\hat{l}$ the the best-response level of intermediation $\theta(\hat{l})=\theta_{\text {min }}$ implies $\alpha E(P)=1$, and farmers are indifferent between making either of the two goods.
} 
$\operatorname{good} 12$

When $R$ is above $\frac{1}{\alpha}$, the farmer's outside option for strawberries is high enough so that making strawberries becomes the dominant strategy. When $R>P^{w}-\frac{\kappa_{F}}{\alpha}$, intermediation is unprofitable and no traders enter. Strawberries are sold to the canning factory which pays $R$. In Figure 2 this corresponds to the region labeled $S-N F$ for Strawberries and No Farm-gate Intermediation. Only in the triangular area, labeled $S-F$ for Strawberries and Farm-gate Intermediation, is there a unique equilibrium where strawberries are produced and sold to intermediaries. This case is depicted in Figure $1 \mathrm{c}$. The two regions are separated by the boundary condition for intermediary entry: $R=P^{w}-\frac{\kappa_{F}}{\alpha}$.

\section{Efficiency Properties of the Equilibrium and Policy Implications}

We now examine the efficiency properties of the equilibrium. Our main result is that efficiency obtains when primitive parameters rule out multiplicity of equilibria. When multiple equilibria are endemic, only the equilibrium where farmers specialize in the export good is constrained efficient. In other words, the source of the inefficiency lies in the coordination failure.

In this section will solve the social planner's problem and describe the constrained efficient allocation in detail.

\subsection{Constrained Efficient Allocation}

A social planner chooses the level of intermediation and the labor that farmers allocate to the production of the export good to maximize the output subject to the constraint that traders and farmers meet randomly. This is a standard notion of constrained efficiency in models with search frictions, see for example Shimer (2005) or Shi (2001).

The planner maximizes the value of output by choosing $\theta^{P}$ and $l^{P}$ :

$$
\max _{l^{P}, \theta^{P}}\left[P^{w}\left(1-e^{-\theta^{P}}\right)+R e^{-\theta^{P}}\right] \alpha l^{P}-\kappa_{F} \theta^{P} I\left[l^{P}>0\right]+\left(1-l^{P}\right)
$$

\footnotetext{
${ }^{12}$ Recall that $\theta_{\min }$ is defined implicitly by $E\left(p / \theta_{\min }\right)=\frac{1}{\alpha}$ and that $\theta(1)=\ln \left(\frac{\left(P^{w}-R\right) \alpha}{\kappa_{F}}\right)$. Using the expression for $E(p)$ from equation (10) gives this boundary as the $R$ and $\kappa_{F}$ such that:

$$
\left.P^{w}\left(1-\left(\frac{\kappa_{F}}{\left(P^{w}-R\right) \alpha}\right)\right)\left(1+\ln \left(\frac{\left(P^{w}-R\right) \alpha}{\kappa_{F}}\right)\right)\right)+R\left(\frac{\kappa_{F}}{\left(P^{w}-R\right) \alpha}\right)\left(1+\ln \left(\frac{\left(P^{w}-R\right) \alpha}{\kappa_{F}}\right)\right)=\frac{1}{\alpha} .
$$
}


where $I\left[l^{P}>0\right]$ is the indicator function taking the value 1 when $l^{P}>0$ and 0 otherwise.

For any positive value of $l^{P}$ the socially optimal level of intermediation solves the first order condition

$$
\alpha l^{P} e^{-\theta^{P}}\left(P^{w}-R\right)-\kappa_{F}=0
$$

This implies that for any given level of $l^{P}$ the socially optimal level of intermediation is

$$
\theta^{P}\left(l^{P}\right)=\max \left\{0, \ln \left(\frac{\alpha l^{P}\left(P^{w}-R\right)}{\kappa_{F}}\right)\right\}
$$

Notice that this expression coincides with the trader best response function for a given level of $l$, indicating that the level of intermediation is not distorted.

Given equation (14), the maximized welfare given in equation $(13)$ is linear in $l^{P}$ so the social planner will set $l^{P}=0$ or to 1 . He will assign all farmers to produce the export good and set $l=1$ when

$$
\left[P^{w}\left(1-e^{-\theta^{P}(1)}\right)+R e^{-\theta^{P}(1)}\right] \alpha-\kappa_{F} \theta^{P}(1) \geq 1
$$

The right-hand side of equation (15) corresponds to $l^{P}=0$ when only the staple is produced so that welfare is 1 . When $l^{P}=1$, welfare is as given in the left-hand side of equation (15). At first sight this condition looks different from the farmers' labor optimality condition

$$
\alpha E(p)>1
$$

However, using equation (14), the social planner's rule for labor allocation can be shown to be equivalent to that of the farmers' 13

Thus, the decentralized equilibrium is potentially inefficient only in the region with multiple equilibria, i.e., region $M$ in Figure 2, Here the decentralized allocation could result in wheat being made, while the social planner would prescribe specialization in strawberries. The reason for the potential inefficiency is the coordination failure. In the following section we will explore policies that can resolve this coordination failure and ensure that the decentralized allocation coincides with the constrained efficient one.

\footnotetext{
${ }^{13}$ Consider:

$$
\alpha\left[P^{w}\left(1-e^{-\theta}(1+\theta)\right)+\operatorname{Re}^{-\theta}(1+\theta)\right] \alpha \geq 1
$$

It can be rearranged as

$$
\left[P^{w}\left(1-e^{-\theta}\right)+R e^{-\theta}\right] \alpha-\alpha\left(P^{w}-R\right) e^{-\theta} \theta \geq 1 .
$$

As $\alpha\left(P^{w}-R\right) e^{-\theta}$ can be replaced by $\kappa_{F}$ due to free entry, equation 15 coincides with equation 16 .
} 


\subsection{Eliminating the Coordination Failure}

We have shown that the only distortion in the competitive allocation is due to the coordination failure that generates the "bad" equilibrium in region $M$ in Figure 2. The natural question to ask is how policy can eliminate the bad equilibrium in the region with multiplicity. If we can ensure that it is the dominant strategy for the farmer to produce the export good, then the bad equilibrium is eliminated and the economy will attain the constrained efficient allocation. One way to do this is to offer a production subsidy. Another is to offer a price support as is often done by export boards. We show below both policies can eliminate multiplicity. The production subsidy however, dominates the price support in terms of welfare, as the later distorts the level of intermediation.

\section{A Production Subsidy}

Suppose the economy is in the region $M$ and the government offers a per unit subsidy slightly above $s=\frac{1}{\alpha}-R$, say $\frac{1}{\alpha}-R+\epsilon$. Then farmers will specialize in the export good no matter what the level of intermediation is. Even with no traders, farmers' expected income from making the export good exceeds that from making the staple: $\alpha\left(\frac{1}{\alpha}-R+\epsilon\right)>1$. Thus, in Figure 1b, such a subsidy makes $l(\theta)=1$ independent of $\theta$. Knowing that farmers will produce the export good, traders will enter, and the bad equilibrium is eliminated.

In other regions the production subsidy is either ineffective or welfare decreasing. In region $W$, for example, farmers have a comparative advantage in the staple and specialize in it. As a result, subsidizing production of strawberries reduces overall welfare. If the economy is in $S-F$ or $S-N F$ farmers always specialize in strawberries and the production subsidy will just be a transfer between the government and the farmers with no real effects on the producer price or production decisions.

Proposition 4. A per unit production subsidy greater than or equal to $1 / \alpha-R$ can eliminate the inefficient equilibrium and raise welfare if the economy is in region $M$. It will lower welfare if the economy is in region $W$, and have no effect otherwise.

\section{Export Board}

What is the effect of an export board that commits to purchase strawberries from the farmer at price $R$ while it obtains $R^{0}$ for them? When $R$ rises beyond $R^{0}$, the board effectively offers insurance to farmers who do not meet a trader. This raises the farmers' reservation price. Note that by offering an $R$ above $\frac{1}{\alpha}$, a board can ensure that farmers specialize in strawberries regardless of the level of intermediation. In region $M$ such an export board eliminates the multiplicity of equilibria. However, in contrast to a production subsidy, a 
higher $R$ reduces the level of intermediation. A lower level of intermediation means that a smaller share of the export good produced reaches the world market. Thus, even if all farmers make strawberries, welfare is below what it would be with a production subsidy.

Figure $1 \mathrm{~b}$ can be used to illustrate the effect of an export board in region $M$. An increase in $R$ raises the expected price as shown in equation (11). This makes the farmer require a lower level of intermediation before switching over to strawberries so that $\theta_{\text {min }}$ moves to the left. Once $R$ reaches $\frac{1}{\alpha}$, farmers are willing to make strawberries even without intermediation so that $l(\theta)=1$ for all $\theta$, and the coordination failure is eliminated. In addition, at every $l$ there is less intermediation so that the $\theta(l)$ curve shifts up. As a result, the equilibrium level of intermediation when strawberries are made falls.

Proposition 5. In region $M$ both per unit production subsidy or an export board that sets $R$ greater than or equal to $1 / \alpha$ can resolve the coordination failure. However, welfare is higher when the production subsidy is used.

This makes perfect sense as the only distortion in the competitive allocation is the coordination failure. A subsidy to production of more than $\frac{1}{\alpha}-R$ fixes this, leaving intermediation unaffected, while a price support that eliminates multiplicity reduces intermediation, introducing an additional distortion.

Given that a board's choice of $R$ has real effects both in terms of eliminating multiplicity and affecting intermediation, it is worth exploring how welfare changes with its choice of $R$. We show that welfare is maximized when the export board sets $R$ exactly equal to $R^{0}$, as long as the export good is produced. In other words, an export board that pays farmer $R$ while selling the produce at $R^{0} \neq R$ distorts the level of intermediation in the competitive allocation. This makes the case for boards that act in the farmer's interests once the coordination failure is resolved by setting $R=R^{0}$.

To see this let $R^{0}$ be the price that the board receives from selling strawberries, and also assume that the board uses no resources in its operation. Then welfare is given by

$$
W=\alpha\left(P^{W}\left(1-e^{-\theta}\right)+R^{0} e^{-\theta}\right)-\kappa_{F} \theta
$$

Note that the share of output that is not sold to the intermediaries is sold at $R^{0}$, while the level of intermediation $\theta$ is a function of $R$, the price set by the export board. Hence, an increase in $R$ affects welfare only via its effect on $\theta$. It reduces revenue by $\alpha\left[\left(P^{W}-R^{0}\right) e^{-\theta} \frac{\partial \theta}{\partial R}\right]$ 
but also reduces costs by $\kappa_{F} \frac{\partial \theta}{\partial R}$. The net effect is

$$
\begin{aligned}
\frac{\partial W}{\partial R} & =\left(\alpha\left(P^{W}-R^{0}\right) e^{-\theta}-\kappa_{F}\right) \frac{\partial \theta}{\partial R} \\
& =\kappa_{F}\left(\frac{P^{W}-R^{0}}{P^{W}-R}-1\right) \frac{\partial \theta}{\partial R} \\
& =0 \text { if } R=R^{0},
\end{aligned}
$$

where we substitute for $e^{-\theta}$ from the free entry condition. Thus, welfare is maximized at $R=R^{0}$. An increase in $R$ reduces intermediation and raises the share of the output disposed of at $R^{0}$ rather than $P^{w}$, which has a negative effect on welfare. It also reduces the resources expended on entry. At $R=R^{0}$, these two just wash out.

\section{Local Markets}

An important aspect of agricultural trade in less developed countries is that farm-gate trade coexists with organized markets. In this section we introduce local markets where farmers can sell the export good at a market clearing price, thus endogenizing $R$. Often such markets are located in regional centers and serve as a meeting point for exporters/intermediaries and farmers. Whether such markets are viable depends on the cost of accessing them for intermediaries and farmers. In the real world such costs are related to the quality of roads and infrastructure.

Selling at the local market is an option that is always available to farmers: when no trader shows up at the farm-gate, he can travel to the local market at cost $T_{M}$ and sell the produce there at the market clearing price $P^{M}$. $T_{M}$ captures the farmer's travel and time costs. Traders who go to the local market pay a sunk cost $\kappa_{M}$. The price in the local market is pinned down by the trader's free-entry condition

$$
\alpha\left(P^{w}-P^{M}\right)=\kappa_{M}
$$

This condition requires that the profits made by a trader choosing to go to the local market be just enough to cover the costs of getting there. Thus the price at the local market is

$$
P^{M}=P^{w}-\frac{\kappa_{M}}{\alpha}
$$

Traders have a choice between going to the local market or the farm-gate. They can go to the farm-gate by paying the sunk cost of $\kappa_{F}$ and buy directly from the farmer if matched. A trader going to the farm-gate understands that the farmer's reservation price is given by 
his pay-off from going to the local market, so that $R=\max \left\{0, P^{M}-\frac{T_{M}}{\alpha}\right\}$. Substituting for $P^{M}$ from equation 19 gives

$$
R=\max \left\{0, P^{w}-\left(\frac{\kappa_{M}+T_{M}}{\alpha}\right)\right\}
$$

Note that the reservation price of the farmer depends only on the sum of the costs of accessing the local market to the farmer and to the trader, and not their distribution over the two agents. The higher the total cost of accessing the local market, the lower is the farmer's outside option. Once this joint cost of accessing the local market becomes so high that the farmer's pay-off to selling at the farm-gate turns negative his reservation price goes to zero. 14 Note also that as there is a continuum of agents, $P^{M}$ and $R$ are not random.

With $R$ given in equation 20 and assuming that $l=1$, the level of intermediation is

$$
\theta(l=1)=\max \left\{0, \ln \left(\frac{\min \left\{\alpha P^{w}, \kappa_{M}+T_{M}\right\}}{\kappa_{F}}\right)\right\}
$$

The level of intermediation depends on whether the farmer finds it profitable to access the local market. When $P^{w} \leq \frac{\kappa_{M}+T_{M}}{\alpha}$ local markets are not viable and the level if intermediation is the same as in the baseline model with $R$ set to 0 so that $\theta=\frac{\alpha P^{w}}{\kappa_{F}}$. Local markets are viable when $P^{w}>\frac{\kappa_{M}+T_{M}}{\alpha}$. In this case the level of intermediation does not depend on the world price, and depends only on the total costs of accessing the local market so that $\theta=\frac{\kappa_{M}+T_{M}}{\kappa_{F}}$. Note that the expression for the level of intermediation in equation (21) incorporates the possibility of no intermediation, i.e. $\theta=0$.

Similarly the expected price at the farm-gate depends on whether the local market is viable. The expected price in the two scenarios is given by

$$
E(p)=\left\{\begin{array}{l}
P^{w}-\frac{\kappa_{M}+T_{F}}{\alpha}(1+\theta) e^{-\theta}=P^{w}-\frac{\kappa_{F}}{\alpha}(1+\theta) \text { if } P^{w}>\frac{\kappa_{M}+T_{M}}{\alpha} \\
P^{w}\left(1-(1+\theta) e^{-\theta}\right) \text { if } P^{w} \leq \frac{\kappa_{M}+T_{M}}{\alpha}
\end{array}\right.
$$

Note that with local markets, the level of intermediation does not depend on the world price, so that the farm-gate price adjusts one-to-one with the world price ${ }^{15}$ Next we proceed to describe the types of equilibria and their properties in the augmented model.

\footnotetext{
${ }^{14}$ This suggests that the price at the farm-gate is not a linear price of distance but has a has a kink in it where the regime changes. This seems a testable implication of the model.

${ }^{15} \mathrm{An}$ increase in the world price directly translates into a higher farmer outside option of $P^{W}-\frac{\kappa_{M}+T_{M}}{\kappa_{F}}$, and a higher upper bound of the price distribution of $p_{\max }=P^{W}-\frac{\kappa_{F}}{\alpha}$. Note that the lower bound and the upper bound of the price offer distribution move by the same amount, so that the price offer distributions shifts to the right but its shape is unchanged.
} 


\section{$3.1 \quad$ Equilibrium}

An equilibrium consists of the objects: $\theta, F(p), l(\theta)$ defined previously, $P^{M}$ defined in equation (19), and the farmer's reservation price $R$ given by equation (20). As in the baseline model, both multiple and unique equilibria are possible. Figure 3 shows the possible equilibrium types as a function of the primitive parameters $\kappa_{M}+T_{M}$ and $\kappa_{F}$, for fixed values of $P^{W}$ and $\alpha$. The line labeled $\kappa_{M}+T_{M}=\alpha P^{W}$ defines the boundary where the farmer's pay-off from going to the local market is 0 , so for values of $\kappa_{M}+T_{M}$ greater than $\alpha P^{W}$ we are back in the baseline setup with $R=0$. Below the line, the payoff from going to the local market pins down the farmer's reservation price.

In the baseline case producing the export good becomes the dominant strategy for farmers when $R$ exceeds $\frac{1}{\alpha}$. With local markets, the analogous condition is that the farmer's pay-off at the local market exceeds that of making the staple: $\alpha P^{w}-\left(\kappa_{M}+T_{M}\right)>1$. In Figure 3 , the line $\kappa_{M}+T_{M}=\alpha P^{w}-1$ gives the boundary where the farmer outside option just ensures specialization in the export good. Below the line, strawberries are produced by all farmers regardless of the prevailing level of intermediation. Above the line, the pay-off from growing the staple is higher than the pay-off from selling at the local market. In this region, whether farmers specialize in the export good or the staple depends on the level of intermediation.

The level of intermediation in turn depends on the ratio between the total cost of accessing the local market, $\kappa_{M}+T_{M}$, and the cost of farm-gate intermediation, $\kappa_{F}$. With access to local markets, the export good can reach the world market in two ways: via the local market or through an intermediary at the farm gate. When $\kappa_{M}+T_{M}<\kappa_{F}$, the technology of farm-gate intermediation is dominated by the technology of local markets, as the latter both costs less and provides certain results. Thus, in Figure 3 farm-gate intermediation is not sustainable below the $45^{0}$ line. Above the $45^{0}$ line, whether intermediaries enter and farm-gate trade exists or not, depends on whether or not farmers make strawberries.

The region labeled $S-F L$ lies below the $\kappa_{M}-T_{M}=\alpha P^{w}-1$ line and above the $45^{0}$ line. In this region farmers make strawberries and intermediaries enter. Here the farmer's decision to make strawberries is independent of the the level of intermediation, because the pay-off at the local market is higher than the payoff from making the staple.

Above the $\kappa_{M}-T_{M}=\alpha P^{w}-1$ line, the farmer's pay-off from selling at the local market is less than what he would obtain from growing wheat. Thus, the local market option no longer ensures strawberry production. Whether strawberries are made or not depends on the level of farm-gate intermediation. In Figure 3 regions $M$ and $W$ lie both above the line $\kappa_{M}-T_{M}=\alpha P^{w}-1$ and above $45^{0}$ line. In region $M$ multiple equilibria are endemic. As in the baseline model, in the "good" equilibrium farm-gate trade coexists with local markets, and in the "bad" equilibrium farmers produce wheat and intermediaries do not enter. In 
region $W$ only wheat is produced. A higher $\kappa_{F}$ reduces farm-gate intermediation until we switch to the region $W$ where only wheat is made. The switch occurs when farmers are indifferent between wheat and strawberries, i.e., $\alpha E(p)=1$, with intermediation at the free entry level. This condition can be rewritten as

$$
\kappa_{M}+T_{M}=\kappa_{F} e^{\left(\frac{\alpha P^{w}-\kappa_{F}-1}{\kappa_{F}}\right)} .
$$

To summarize, in Figure 3, in region marked $W$ only wheat is made, in region $M$ there is multiplicity of equilibria. Only strawberries are made in the regions $S-F L$ and $S-L$. In the $S-F L$ region where both farm gate intermediation and local markets operate while in the $S-L$ region only local markets operate.

\subsection{International Prices and Domestic Outcomes}

In this section we explore the effect of changes in international prices on equilibrium outcomes and welfare. The model predicts a very different pass through of changes in the world price to the producer price depending on whether farmers have access to local markets. Proposition 6 summarizes the findings:

\section{Proposition 6.}

(i) Pass-through of world prices is complete when farmers have access to local markets but is incomplete when they face a fixed outside option.

(ii) With an exogenous outside option, pass-through falls as the outside option rises.

(iii) A higher $P^{w}$ makes production of strawberries more profitable all else given, with or without local markets. With local markets, having $P^{w}>\frac{1+\kappa_{M}+T_{M}}{\alpha}$ ensures specialization in strawberries.

(iv) Welfare gains/losses from an increase/decrease in the world price $P^{w}$ are larger in the presence of local markets.

Here we sketch the proof.

(i) Consider the pass-through of world price $P^{w}$ into the farm-gate price. With farmers having access to local markets, a rise in the world price has no effect on the level of intermediation. So from equation (22), it is easy to see that the pass-through of changes in $P^{w}$ is complete as the level of intermediation is unaffected. Intuitively, a rise in $P^{w}$ is accompanied by the equivalent rise in the (endogenous) reservation price. Thus, traders' profits remain the same and the change in the world price is entirely passed into the farm-gate price.

\footnotetext{
${ }^{16}$ Substituting for $R$ from equation $\sqrt{20}$ into $\theta=\ln \frac{\alpha\left(P^{w}-R\right)}{\kappa_{F}}$ gives $\theta=\ln \frac{\kappa_{M}+T_{M}}{\kappa_{F}}$. Substituting for these values of $R$ and $\theta$ into the expected price given in equation 22 yields the result.
} 
Without access to local markets, the pass-through is incomplete. In contrast to the previous case, a higher $P^{w}$ not only increases the farm-gate price directly but also through greater intermediation. However, the reservation price remains constant at $R$, and those farmers who do not meet a trader are not affected by a higher $P^{w}$. So expected farm-gate price rises by less than the world price.

More formally, the pass-through is given by differentiating equation 10 with respect to $P^{w}$ :

$$
\begin{aligned}
\frac{\partial E(p \mid \theta(l=1))}{\partial P^{w}} & =\frac{\partial E(p)}{\partial P^{w}}+\frac{\partial E(p)}{\partial \theta} \frac{\partial \theta}{\partial P^{w}} \\
& =1-e^{-\theta}<1 \text { for } \theta>0
\end{aligned}
$$

where we take advantage of the fact that $\frac{\partial \theta}{\partial P^{w}}=\frac{1}{P^{w}-R}$.

(ii) From equation (23) the extent of pass-through is equal to the probability of meeting at least one trader. As $R$ rises intermediation falls, and as intermediation falls so does the probability of meeting at least one trader. Thus, pass-through is highest when $R$ is zero. Note that the pass through is also smaller in the short run (where the level of intermediation is fixed) than in the long run where it adjusts.

An empirical study, Fafchamps and Hill (2008), finds that the pass-through of the changes in world commodity price to the producer prices is only partial. Our model suggests that this happens when farmers are in a remote location where local markets are not viable due to high cost of travel for farmers and traders.

(iii) Figures 4 and 5 show how a higher $P^{w}$ makes production of strawberries more likely both with and without local markets.

Without local markets, as depicted in Figure 4, a higher $P^{w}$ shifts the boundary condition for intermediary entry $R=P^{w}-\frac{\kappa_{F}}{\alpha}$ outward, as shown by the downward sloping dashed line. The expected farm-gate price also rises, and the locus of points where farmers are indifferent between wheat and strawberries, i.e., where $\alpha E(p)=1$, also shifts to the right. As a result the regions $S-F$ and $M$ expand at the expense of regions $S-N F$ and $W$ respectively.

With local markets, Figure 5a shows the equilibrium types for a given level of $\alpha P^{w}$ while Figure $5 \mathrm{~b}$ shows them after a $50 \%$ increase in $P^{w}$. The line $\kappa_{M}+T_{M}=\alpha P^{w}-1$, where pay-off at the local market just ensures the production of strawberries, and the line $\kappa_{M}+T_{M}=\alpha P^{w}$, where the pay-off at the local market hits zero, both shift up. As a result the regions $S-F L$ and $S-L$, where farmers always make strawberries expand. The region $M$ where the coordination failure is endemic now occurs at a higher level of $\kappa_{M}+T_{M}$.

(iv) Finally, we show that welfare gains from an increase in the world price are higher when 
farmers have access to local markets. This is because local markets remove the inefficiency associated with intermediation. Without local markets, the export good produced by the unmatched farmers is disposed of at $R$ rather than being sold at $P^{w}$ through intermediaries.

In the baseline case, total welfare is given by equation (13). When $l=1$ the expression simplifies to

$$
W=\alpha\left(P^{w}\left(1-e^{-\theta}\right)+R e^{-\theta}\right)-\kappa_{F} \theta .
$$

Differentiating equation (24) with respect to $P^{w}$ shows the change in welfare is exactly equal to the share of output that is sold at the world market:

$$
\begin{aligned}
\frac{\partial W}{\partial P^{w}} & \left.=\alpha\left(1-e^{-\theta}\right)+\left(\alpha\left(P^{w}-R\right) e^{-\theta}-\kappa_{F}\right) \frac{\partial \theta}{\partial P^{w}}\right) \\
& =\alpha\left(1-e^{-\theta}\right)
\end{aligned}
$$

When farmers have access to a local market each unit of the export good made is sold at $P^{w}$. The expenditure on farm-gate intermediation is $\kappa_{F} \theta$. With probability $e^{-\theta}$ farmers do not meet an intermediary at the farm-gate and sell the produce at a local market. The total expenditure for traders and farmers at the local market is given by $\left(\kappa_{M}+T_{M}\right) e^{-\theta}$. So welfare in the constrained efficient allocation $W_{L}$ when the export good is made is given by

$$
W_{L}=\alpha P^{w}-\kappa_{F} \theta-\left(\kappa_{M}+T_{M}\right) e^{-\theta}
$$

In this case $\theta$ is independent of $P^{w}$ so a change in welfare is

$$
\frac{\partial W_{L}}{\partial P^{w}}=\alpha
$$

\section{Policy}

In our model the interaction of several market frictions can prevent the efficient allocation of resources. In fact, the economy can end up specializing in the commodity in which it has a comparative disadvantage. In what follows, we take the existence of these frictions as given and look at the efficacy of alternative policy instruments and their welfare implications. We consider the effect of reductions of transport costs, as would occur with better roads or railways, agricultural extension programs, which raise $\alpha$, and the relaxation of SPS requirements. 


\subsection{SPS requirements}

In the previous section, we discussed how changes in $P^{w}$, the world price, affect welfare and equilibrium outcomes. So far we have treated $P^{w}$ as a competitive price determined in the world market. Here we argue that in developing countries exporters face low effective world prices due to SPS requirements.

Meeting SPS requirements involves restrictions on agricultural practices. For example, pesticide residue may be limited to lower levels than permitted domestically. In addition, the produce has to be inspected. While the fees for SPS inspections may not be large, the risk associated with failing to pass them can be substantial. For example, Ferrier, Petersen and Landes (2012) estimates that in the case of Alphonso mangoes from India, the direct costs of production and SPS inspection fees account for about $30 \%$ of the final price. This cost estimate, however, ignores the risk of failing the SPS inspection, which reduces the effective price that the exporters face. Roy and Thorat (2008), who focus on exports of grapes from India, document that failure rates in meeting SPS requirements for new exports are as high as $80 \%$.

In short, we can think of the effective price that exporters face, i.e., $P_{S P S}^{w}$, as the function of four things: the probability that the SPS requirements are met in the inspection $\lambda$, the sunk SPS inspection fee $\psi$, the scrap value of the goods for export if they fail the inspection $S$, and the price of the good after the SPS inspection has been passed $P^{w}$. Then $P_{S P S}^{w}$ can be written as

$$
P_{S P S}^{w}=P^{w} \lambda-\psi+(1-\lambda) S
$$

Note, $S$ can be 0 or positive. If the exports are inspected upon arrival, products that do not meet the SPS requirements are destroyed, so $S=0$. If they are inspected and certified in the country of origin, then $S$ may be positive, suggesting that ensuring SPS requirements are satisfied domestically increases the effective price of exports. Similarly, policies that reduce $\lambda$ and $\psi$ increase $P_{S P S}^{w}$, the effective export price. The effects of policies that ease SPS requirements are identical to the effects of the lower world price described in the previous section. Since a higher effective price expands the regions where strawberries are made, our model suggests that SPS requirements could prove to a significant barrier to exports.

Furthermore, Roy and Thorat (2008) document that SPS inspection failure rates fell to $1 \%$ within a year of exporting, suggesting that $\lambda$ falls as exporters gain experience in meeting the SPS requirements. To the extent that exporters learn from one another, exporting may raise $\lambda$ not just for a particular exporter, but also for other actual or potential exporters. For example, new exporters could hire knowledgeable workers from experienced exporters 
as they prepare to enter. For such reasons pioneers may not internalize the benefits of a lower $\lambda$ in the future. As a result, even products that are viable in the long run may not be produced without interventions of some kind. Partnering with multinationals who have experience in meeting such requirements, providing insurance for early exporters, or direct government involvement are possible remedies.

\subsection{The Role of Agricultural Extension Programs}

In many countries, including developed ones, considerable effort is devoted to agricultural extension programs. These programs are usually directed towards raising productivity in agriculture by introducing farmers to best practice techniques. In our model, we think of agricultural extension programs as raising $\alpha$, the productivity of the farmer in strawberries. Increasing $\alpha$ can eliminate multiple equilibria and encourage production of the export good. Whether local markets are viable or not, higher productivity in the export good increases the farm-gate price, and welfare overall.

In the baseline model, the effect of a higher $\alpha$ is twofold. First, higher productivity raises welfare directly. Second, it raises the level of intermediation as it increases traders' expected profits. In Figure 2 the line $R=\frac{1}{\alpha}$ shifts downward as $\alpha$ increases, and shrinks the $M$ region where multiple equilibria occur. A higher $\alpha$ also increases the level of intermediation, especially for low values of $R$. This rotates the downward sloping line, where intermediation is just viable, to the right. With a higher $\alpha$ farmers specialize in strawberries at lower farmgate price, which shifts the $\alpha E(p)=1$ condition separating the region $M$ and $W$ to the right. All of these expand the region where strawberries are made.

In the presence of local markets a change in $\alpha$ has the same effect as a change in $P^{w}$, which was discussed in section 3.2 . We now turn to the implications of changes in $\alpha$ for welfare.

Proposition 7. With or without local markets, expected price and welfare increase in $\alpha$. The increase is greater in the presence of local markets.

The effect on the farm-gate price is given by

$$
\frac{\partial E(p)}{\partial \alpha}=\frac{\kappa \theta}{\alpha^{2}}>0 \text { for } \theta>0
$$

The effect on welfare is given by

$$
\frac{\partial W}{\partial \alpha}=P^{w}-\frac{\kappa_{F}}{\alpha}>0
$$


When farmers can access a local market, the effect of a change on the farm-gate price and welfare are given by

$$
\frac{\partial E_{L}(p)}{\partial \alpha}=\frac{-\kappa_{F}(1+\theta)}{\alpha^{2}}
$$

and

$$
\frac{\partial W_{L}}{\partial \alpha}=P^{w}
$$

respectively.

The intuition behind the result has to do with the fact that with local markets the entire output reaches the export market either via farm-gate trade or local markets, while without local markets only a part does so.

\subsection{The Role of Infrastructure}

A good deal of attention has been paid recently to the role played by infrastructure in facilitating market access and encouraging development. Our model suggests that connecting farmers to local markets, i.e., reducing $\kappa_{M}$ or $T_{M}$, is more efficacious than connecting farmers directly to intermediaries, i.e., reducing $\kappa_{F}$. This is for two reasons. First, reducing $\kappa_{M}$ or $T_{M}$ by enough eliminates multiplicity, while reducing $\kappa_{F}$ has no such effect as is evident from Figure 3. Second, it can be shown that welfare is more responsive to changes in $\kappa_{M}$ and $T_{M}$ than to changes in $\kappa_{F}$. This suggests that if local markets are present and the cost of reducing $\kappa_{M}$ and $\kappa_{F}$ are similar, then reducing $\kappa_{M}$ or $T_{M}$ is the more effective policy.

Proposition 8. Welfare is more responsive to changes in $\kappa_{M}$ than to changes in $\kappa_{F}$.

Welfare in the absence of local markets is given in equation 18 and welfare with local markets is given in equation(26). Differentiate each expression with respect to $\kappa_{F}$ to see that the change in welfare in response to a change in $\kappa_{F}$ is the same both with or without access to local markets, and is given by

$$
\frac{\partial W}{\partial \kappa_{F}}=\frac{\partial W_{L}}{\partial \kappa_{F}}=-\theta .
$$

This is because a change in $\kappa_{F}$ has same effect on the level of intermediation, regardless of whether farmers have access to a local market or not.

In the presence of local markets, the change in welfare due to a change in $\kappa_{M}$ is given 
by 17

$$
\frac{\partial W_{L}}{\partial \kappa_{M}}=-e^{-\theta}
$$

and it is clearly larger than the corresponding change in welfare due to a change in $\kappa_{F}$. Intuitively, this result follows from the observation that matches at the farm-gate are not certain while those in the local market are.

Our results are consistent with the recent work on the importance of the lower transport costs for development as discussed in the introduction. It is important to note, that while we have treated $\kappa_{F}$ and $\kappa_{M}+T_{M}$ as independent parameters, in reality policies that affect one are likely to impact the other. For example, improvements to rural roads would reduce $\kappa_{M}+T_{M}$ as well as $\kappa_{F}$.

\section{Conclusion}

In this paper we develop a model of intermediation in the absence of binding contracts and apply it to a Ricardian setting. This provides a new reason for why developing countries specialize producing staples despite the availability of what seem to be more lucrative options. The inability of farmers and traders to contract on price makes farmers subject to hold-up. The anticipation of such hold-up in turn prevents farmers from exploring seemingly lucrative options.

A new role for marketing boards and for local markets emerges. Both can provide farmers an outside option that discourages opportunistic behavior by intermediaries. Local markets prove to be particularly effective policies in this regard. Their presence also enhances efficiency as the entire output finds its way to the world market despite intermediation frictions. Conversely, SPS requirements are shown to be particularly damaging as they make the inefficiencies associated with hold-up more likely. A case for intervention arises when there is learning by doing in meeting SPS requirements that spills over to other producers. Incomplete pass-through of export prices to producers at the farm-gate, a pattern observed especially in remote areas, emerges naturally in this setting as well.

\section{References}

Antras, Pol, and Arnaud Costinot. 1993. "Intermediated Trade." Quarterly Journal of

\footnotetext{
${ }^{17}$ Also recall as far as facilitating local market access, it makes no difference whether the fall in cost is on the part of farmers or traders: only their sum matters so that $\frac{\partial W_{L}}{\partial \kappa_{M}}$ is the same as $\frac{\partial W_{L}}{\partial T_{M}}$.
} 
Economics, 126(3): 1319-1374.

Antras, Pol, and C Fritz Foley. 2011. "Poultry in Motion: a Study of International Trade Finance Practices." National Bureau of Economic Research.

Banerjee, Abhijit V., and Esther Duflo. 2000. "Reputation Effects and the Limits of Contracting: A Study of the Indian Software Industry." The Quarterly Journal of Economics, 115(3): 989-1017.

Burdett, Kenneth, and Dale T Mortensen. 1998. "Wage Differentials, Employer Size, and Unemployment." International Economic Review, 257-273.

Burdett, Kenneth, and Kenneth L Judd. 1983. "Equilibrium price dispersion." Econometrica: Journal of the Econometric Society, 955-969.

Casaburi, Lorenzo, Rachel Glennerster, and Tavneet Suri. 2013. "Rural Roads and Intermediated Trade: Regression Discontinuity Evidence from Sierra Leone." Available at SSRN 2161643.

Caselli, Francesco. 2005. "Accounting for Cross-country Income Differences." Handbook of Economic Growth, 1: 679-741.

Costinot, Arnaud, and Dave Donaldson. 2012. "Ricardo's Theory of Comparative Advantage: Old Idea, New Evidence." National Bureau of Economic Research.

Costinot, Arnaud, Dave Donaldson, and Cory Smith. 2012. "Evolving Comparative Advantage and the Impact of Climate Change in Agricultural Markets: Evidence from a 9 Million-Field Partition of the Earth." Journal of Political Economy, Forthcoming.

Delgado, Christopher, C Narrod, and M Tiongco. 2003. "Policy, Technical and Environmental Determinants and Implications of the Scaling-up of Livestock Production in Four Fast-Growing Developing Countries: A Synthesis." International Food Policy Research Institute.

Fafchamps, Marcel, and Ruth Vargas Hill. 2005. "Selling at the Farmgate or Traveling to Market." American Journal of Agricultural Economics, 87(3): 717-734.

Fafchamps, Marcel, and Ruth Vargas Hill. 2008. "Price Transmission and Trader Entry in Domestic Commodity Markets." Economic Development and Cultural Change, 56(4): 729-766. 
Fafchamps, Marcel, Eleni Gabre-Madhin, and Bart Minten. 2005. "Increasing returns and market efficiency in agricultural trade." Journal of Development Economics, 78(2): 406-442.

Ferrier, Peyton, Everett Petersen, and Maurice Landes. 2012. Specialty Crop Access to US Markets: A Case Study of Indian Mangoes. United States Department of Agriculture, Economic Research Service.

Galenianos, Manolis, and Philipp Kircher. 2008. "A model of Money with Multilateral Matching." Journal of Monetary Economics, 55(6): 1054-1066.

Greif, Avner. 2005. "Commitment, Coercion, and Markets: The Nature and Dynamics of Institutions Supporting Exchange." In Handbook of New Institutional Economics. 727-786. Springer.

Hausmann, Ricardo, and Dani Rodrik. 2003. "Economic Development as Selfdiscovery." Journal of Development Economics, 72(2): 603-633.

Hausmann, Ricardo, Jason Hwang, and Dani Rodrik. 2007. "What you Export Matters." Journal of Economic Growth, 12(1): 1-25.

Hirschman, Albert O. 1988. The Strategy of Economic Development. Westview Press Boulder.

Kranton, Rachel, and Anand V Swamy. 2008. "Contracts, Hold-up, and Exports: Textiles and Opium in Colonial India." The American Economic Review, 967-989.

Krishna, Vijay. 2009. Auction Theory. Academic Press.

Lagakos, David, and Michael E Waugh. 2013. "Selection, agriculture, and cross-country productivity differences." The American Economic Review, 103(2): 948-980.

Macchiavello, Rocco, and Ameet Morjaria. 2012. "The Value of Relationships: Evidence from a Supply Shock to Kenyan Flower Exports." Working paper.

McMillan, John, and Christopher Woodruff. 1999. "Interfirm Relationships and Informal Credit in Vietnam." The Quarterly Journal of Economics, 114(4): 1285-1320.

Mitra, Sandip, Dilip Mookherjee, Maximo Torero, and Sujata Visaria. 2013. "Asymmetric Information and Middleman Margins: An Experiment with West Bengal Potato Farmers." 
Murphy, Kevin M., Andrei Shleifer, and Robert W. Vishny. 1989. "Industrialization and the Big Push." Journal of Political Economy, 97(5): 1003-1026.

Nurkse, Ragnar. 1966. "Problems of Capital Formation in Underdeveloped Countries."

Osborne, Theresa. 2005. "Imperfect Competition in Agricultural Markets: Evidence from Ethiopia." Journal of Development Economics, 76(2): 405-428.

Rosenstein-Rodan, Paul N. 1943. "Problems of Industrialisation of Eastern and Southeastern Europe." The Economic Journal, 202-211.

Roy, Devesh, and Amit Thorat. 2008. "Success in High Value Horticultural Export Markets for the Small Farmers: The Case of Mahagrapes in India." World Development, 36(10): 1874-1890.

Shimer, R. 2005. "The Assignment of Jobs in an Economy with Coordination Frictions." Journal of Political Economy.

Shi, Shouyong. 2001. "Frictional Assignment. I. Efficiency." Journal of Economic Theory, 98(2): 232-260.

Sotelo, Sebastian. 2013. "Trade Frictions and Agricultural Productivity: Theory and Evidence from Peru." Unpublished manuscript, University of Chicago. 


\section{$5.1 \quad$ Appendix 1}

Proof of Proposition 1: First, we show that the support starts at $R$, has no gaps and the distribution function is continuous, i.e., the density function has no mass points. Since no farmer will accept a price below $R$, the support of $F(\cdot)$ cannot include any such points. Suppose the support of $F(\cdot)$ starts at $\underline{p}>R$. Then a trader who bids a price in the interval $[R, \underline{p})$ will only win if there are no other traders, i.e., with probability $P_{0}=e^{-\theta}$. His expected profit is:

$$
\pi^{T}(p)=\left(P^{w}-p\right) \alpha l^{*} e^{-\theta},
$$

which are decreasing in $p$. Thus, the trader would be better off charging $R$, or any price in $[R, \underline{p})$ than offering $\underline{p}$ which contradicts the assumption that $\underline{p}$ is in the support of the mixed strategy equilibrium.

Next, we establish that there are no gaps or atoms in the support of the distribution.

Let us first rule out gaps in the support of the distribution. Suppose there is a gap in the support of $F(\cdot)$ : no one bids in the interval $\left(p^{\prime}, p^{\prime \prime}\right)$. If there is no mass point at $p^{\prime \prime}$, then a trader who posts a price $p^{*} \in\left(p^{\prime}, p^{\prime \prime}\right)$ will be better off than bidding $p^{\prime \prime}$, as the probability of winning does not decrease, but the profit margin rises. Hence, there are no gaps in the support unless there is a mass point at $p^{\prime \prime}$. Such a mass point would cause a jump down in profits at prices just below $p^{\prime \prime}$, and validate the gap in support of the posited price distribution. Can we rule out such atoms at $p^{\prime \prime}$ ? Yes, we can. If there is an atom at $p^{\prime \prime}$, then bidding $p^{\prime \prime}+\varepsilon$ causes a discrete jump in trader's profits as he increases the offer price only marginally, but this increases his probability of winning discretely.

The same argument rules out atoms at any $\widehat{p}$ in the interior of the support of the distribution or at $R$ : bidding $p=\widehat{p}+\varepsilon$ causes a discrete jump in trader's profits as he increases the offer price only marginally, but this increases his probability of winning discretely. In equilibrium all prices in the support must yield the same profits, hence such mass points cannot occur. They cannot even occur at the upper end of the support. As will be confirmed later, the upper end of the distribution support is given by $p^{\max }<P^{w}$. If there were a mass point at $p^{\max }$, raising $p$ slightly above $p^{\max }$ must raise profits which rules out a mass point at $p^{\max }$.

Next we can use the property of the equality of payoffs at every point of the support to obtain the explicit expression for the cumulative distribution of bids, $F(p)$. Equating the expected profits at an arbitrary price $p$ and expected profits at the lower end of the support $R$, i.e., setting $\pi^{T}(p)=\pi^{T}(R)$, we can solve for the bidding function of the trader as a 
function of world price $\left(P^{w}\right)$, market thickness $(\theta)$, and the farmer's outside option $(R)$ :

$$
\begin{aligned}
\left(P^{w}-p\right) e^{-\theta(1-F(p))} & =\left(P^{w}-R\right) e^{-\theta} \\
e^{\theta F(p)} & =\frac{\left(P^{w}-R\right)}{\left(P^{w}-p\right)} \\
F(p) & =\frac{1}{\theta} \ln \left(\frac{P^{w}-R}{P^{w}-p}\right) .
\end{aligned}
$$

At the upper end of the support the cumulative density function equals unity. Hence solving

$$
F\left(p^{\max }\right)=1=\frac{1}{\theta} \ln \left(\frac{P^{w}-R}{P^{w}-p^{\max }}\right)
$$

for $p^{\max }$ yields the expression for the upper end of the support:

$$
p^{\max }=P^{w}\left(1-e^{-\theta}\right)+e^{-\theta} R .
$$

\section{Proof of Lemma 1:}

By definition, the expected value of the price the farmer gets is

$$
\begin{aligned}
E(p) & =\sum_{k=0}^{\infty} Q_{k} E_{k}(p) \\
& =Q_{0} R+\sum_{k=1}^{\infty} Q_{k}\left[\int_{R}^{p_{\max }} p g_{k}(p) d p\right] \\
& =Q_{0} R+\sum_{k=1}^{\infty} Q_{k}\left[\int_{R}^{p_{\max }} p k[F(p)]^{k-1} f(p) d p\right],
\end{aligned}
$$

where $Q_{k}=\frac{\theta^{k}}{k !} e^{-\theta}, G_{k}(p)=[F(p)]^{k}, g_{k}(p)=k[F(p)]^{k-1} f(p)$.

First we obtain the expected price when $k$ traders show up and then take the expectations over all possible $k$. The expected price conditional on the number of traders is

$$
\begin{aligned}
E_{k}(p) & =\int_{R}^{p_{\max }} p g_{k}(p) d p \\
& =k \int_{R}^{p_{\max }} p f(p)[F(p)]^{k-1} d p \\
& =\frac{k}{\theta^{k}} \int_{R}^{p_{\max }}\left[\ln \left(\frac{P^{w}-R}{P^{w}-p}\right)\right]^{k-1} \frac{p}{P^{w}-p} d p \text { for } k \geq 1
\end{aligned}
$$


We start by solving for the indefinite integral, a key part of $E_{k}(p)$

$$
\int\left[\ln \left(\frac{P^{w}-R}{P^{w}-p}\right)\right]^{k-1} \frac{p}{P^{w}-p} d p
$$

To do so we change variables. Let $x=\ln \left(\frac{P^{w}-R}{P^{w}-p}\right)$, so that $p$ in terms of $x$ is $p=P^{w}-$ $e^{-x}\left(P^{w}-R\right)$. and the corresponding differential $d p=e^{-x}\left(P^{w}-R\right) d x$. Using the change of variables the integral (38) becomes

$$
\begin{array}{r}
\int x^{k-1}\left[e^{x} \frac{P^{w}}{\left(P^{w}-R\right)}-1\right] e^{-x}\left(P^{w}-R\right) d x \\
=P^{w} \int x^{k-1} d x-\left(P^{w}-R\right) \int e^{-x} x^{k-1} d x \\
=P^{w} \frac{x^{k}}{k}-\left(P^{w}-R\right)\left[x^{k-1} e^{-x}(-1)-(k-1) \int(-1) e^{-x} x^{k-2} d x\right] \\
=P^{w} \frac{x^{k}}{k}+\left(P^{w}-R\right) e^{-x}(k-1) !\left[\frac{x^{k-1}}{(k-1) !}+\frac{x^{k-2}}{(k-2) !}+. .+1\right] \\
=P^{w} \frac{x^{k}}{k}+\left(P^{w}-R\right)(k-1) ! e^{-x}\left[\sum_{j=0}^{k-1} \frac{x^{j}}{j !}\right]
\end{array}
$$

Substituting back to obtain the expression above in terms of $p$

$$
\begin{aligned}
\int_{R}^{p_{\max }}\left[\ln \left(\frac{P^{w}-R}{P^{w}-p}\right)\right]^{k-1} \frac{p}{P^{w}-p} d p=(1)+(2) \\
(1)=\left.\frac{P^{w}}{k}\left[\ln \left(\frac{P^{w}-R}{P^{w}-p}\right)\right]^{k}\right|_{R} ^{p^{\max }} \\
=\frac{P^{w}}{k}\left[\ln \left(\frac{P^{w}-R}{P^{w}-p^{\max }}\right)\right]^{k}-\frac{P^{w}}{k}\left[\ln \left(\frac{P^{w}-R}{P^{w}-R}\right)\right]^{k} \\
=\frac{P^{w}}{k}\left[\ln \left(e^{\theta}\right)\right]^{k}-0 \\
=\frac{P^{w}}{k} \theta^{k}
\end{aligned}
$$


and

$$
\begin{aligned}
(2) & =\left.\left(P^{w}-R\right)(k-1) ! \frac{P^{w}-p}{P^{w}-R}\left[\sum_{j=0}^{k-1} \frac{\left[\ln \left(\frac{P^{w}-R}{P^{w}-p}\right)\right]^{j}}{j !}\right]\right|_{R} ^{p_{\max }} \\
& =(k-1) !\{\left(P^{w}-R\right) e^{-\theta}\left[\sum_{j=0}^{k-1} \frac{\left[\ln \left(e^{\theta}\right)\right]^{j}}{j !}\right]-\underbrace{\left.\left(P^{w}-R\right)\left[1-\sum_{j=0}^{k-1} \frac{\left[\ln \left(\frac{P^{w}-R}{P^{w}-R}\right)\right]^{j}}{j !}\right]\right\}}_{\left(P^{w}-R\right)} \\
& =(k-1) !\left(P^{w}-R\right)\left\{e^{-\theta}\left[\sum_{j=0}^{k-1} \frac{\theta^{j}}{j !}\right]-1\right\} \\
& \left.=\left(P^{w}-R\right)(k-1) !\left\{e^{-\theta} \sum_{j=0}^{k-1} \frac{\theta^{j}}{j !}-1\right)\right\} .
\end{aligned}
$$

In evaluating the integrals we use the fact that $P^{w}-p^{\max }=e^{-\theta}\left(P^{w}-R\right)$. 


$$
R<\frac{1}{\alpha}
$$

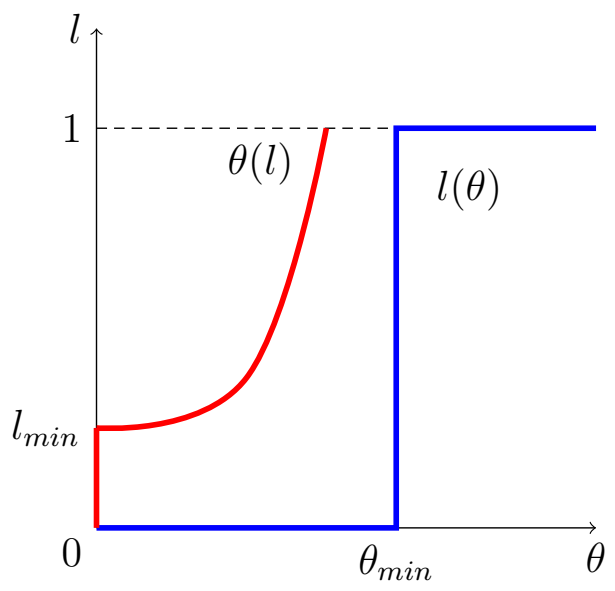

(a) Unique Equilibrium (W)

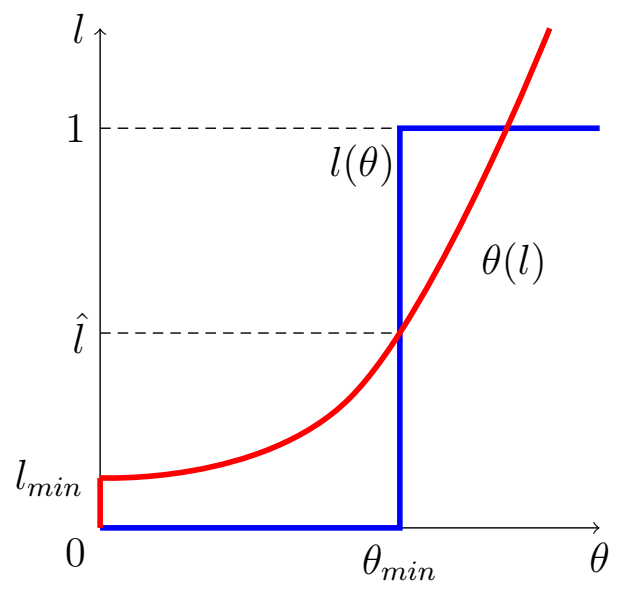

(b) Multiple Equilibria (M)

$$
R \geq \frac{1}{\alpha}
$$

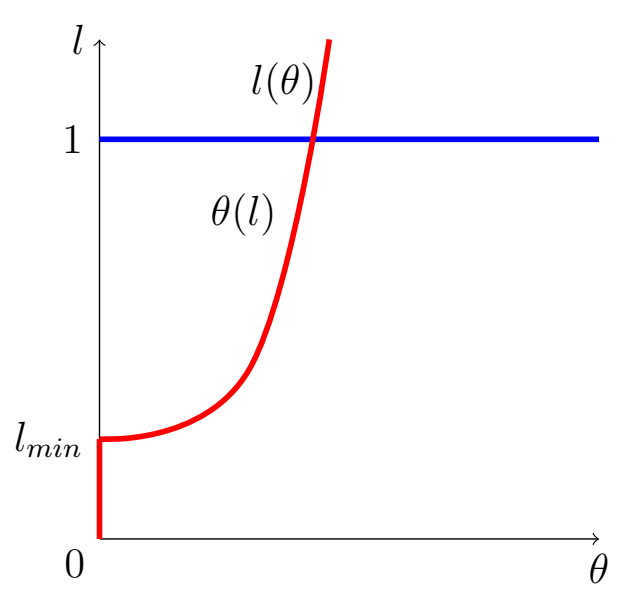

(c) Unique Equilibrium (S-F)

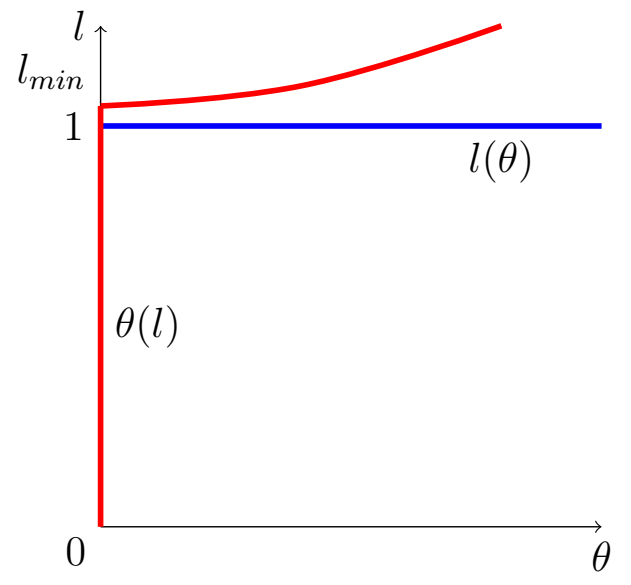

(d) UniqueEquilibrium (S-NF)

Figure 1: Types of equilibria. 


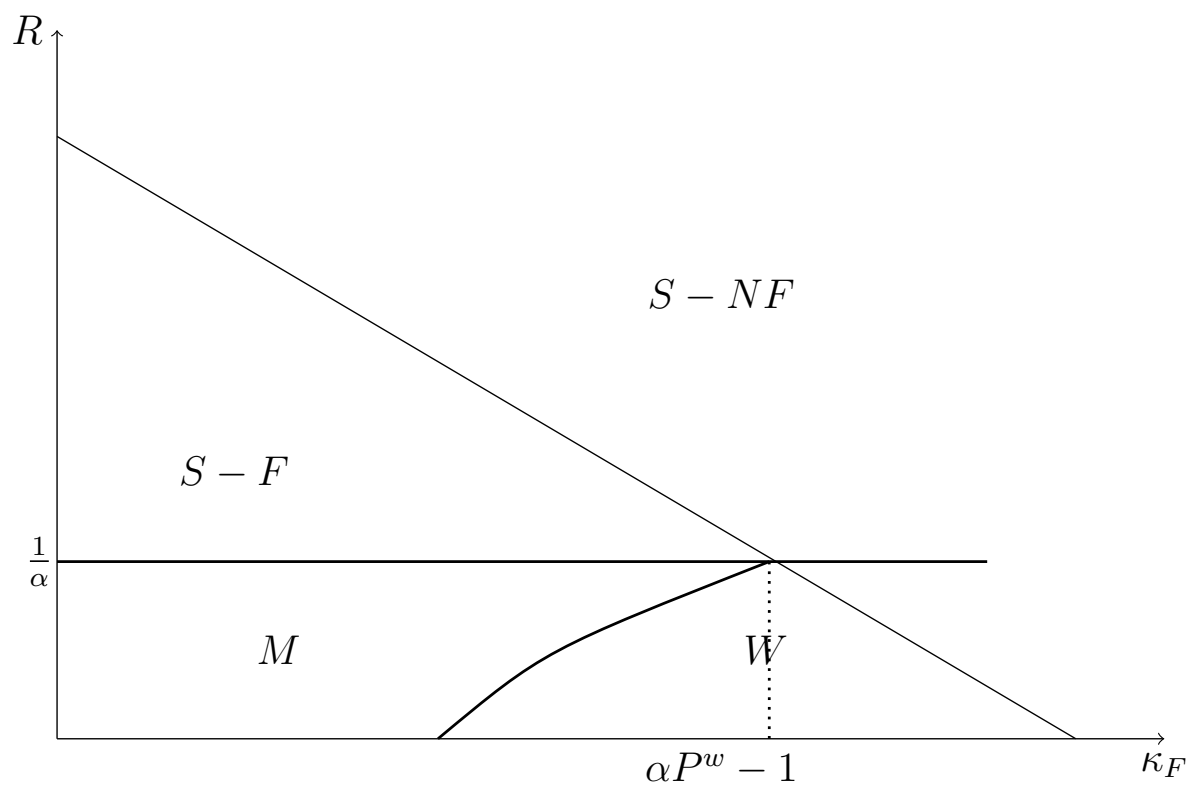

Figure 2: Equilibrium Types in the $\mathrm{R}$ and $\kappa_{F}$ space for sufficiently high $P^{w}$ and $\alpha$

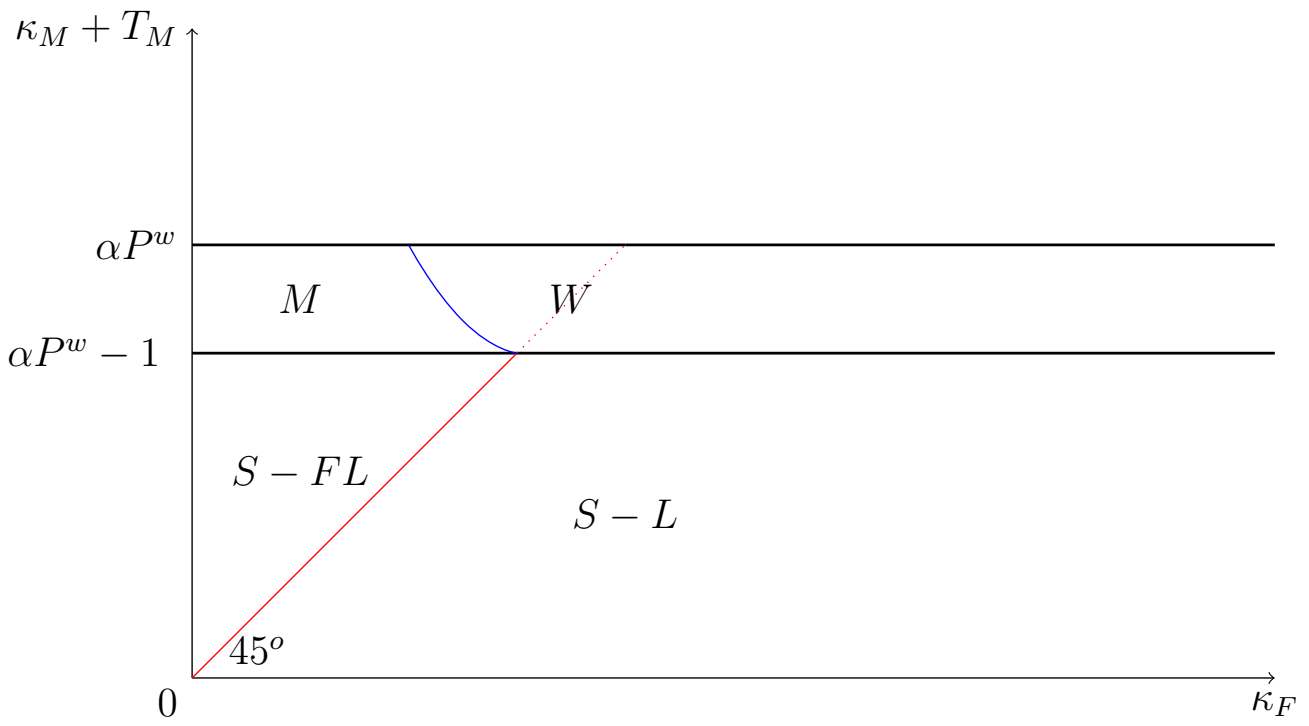

Figure 3: Equilibrium Types in the $\kappa_{M}+T_{M}$ and $\kappa_{F}$ space for sufficiently high $P^{w}$ and $\alpha$ 


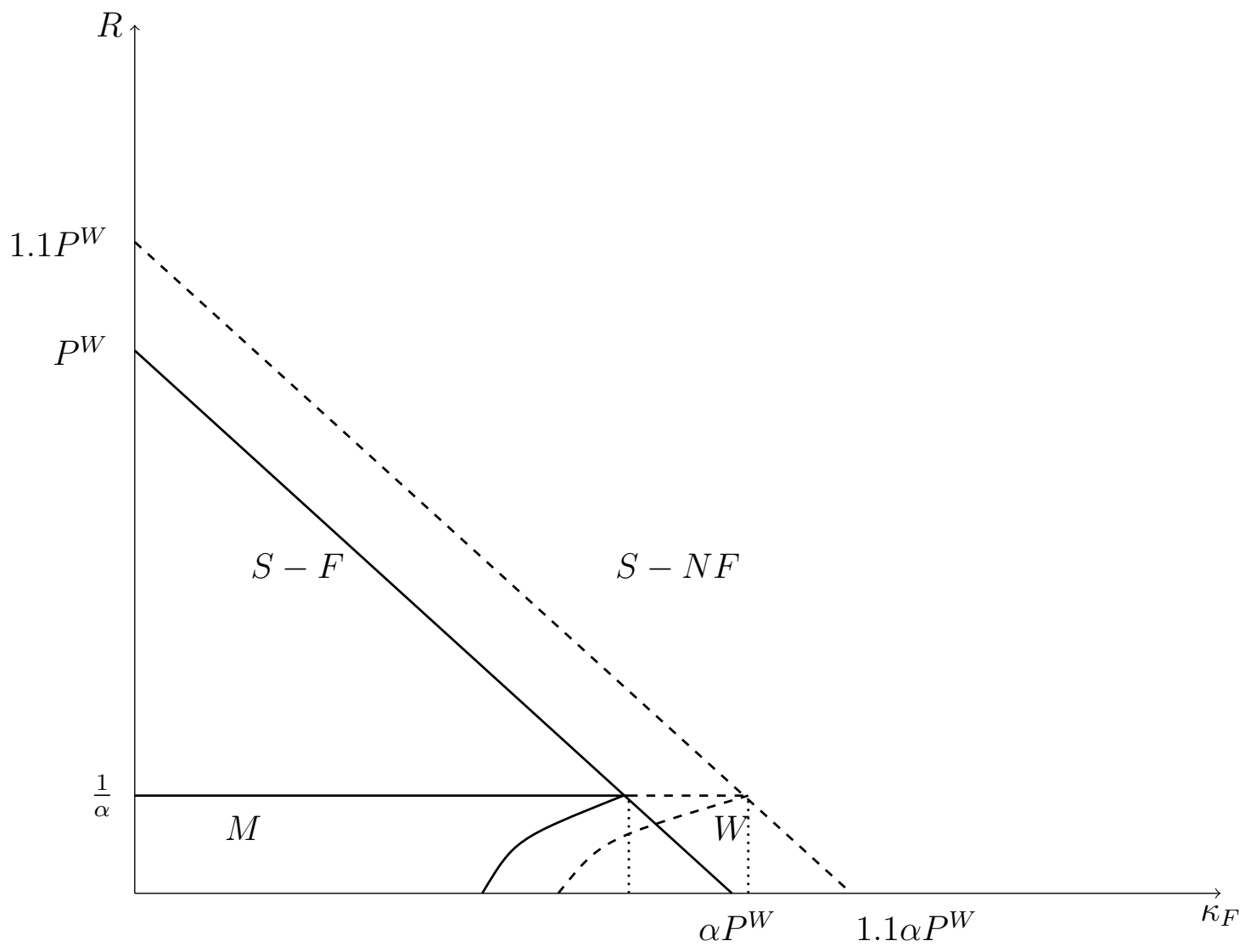

Figure 4: The dotted and the shifted blue line describe the new equilibria regions when $P^{w}$ falls. The $\mathrm{M}$ region and the P-I regions shrink.

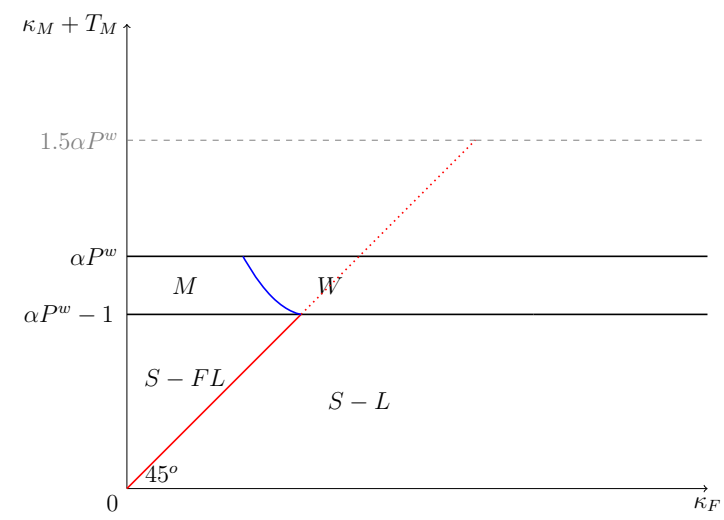

(a) $\alpha, P^{W}$

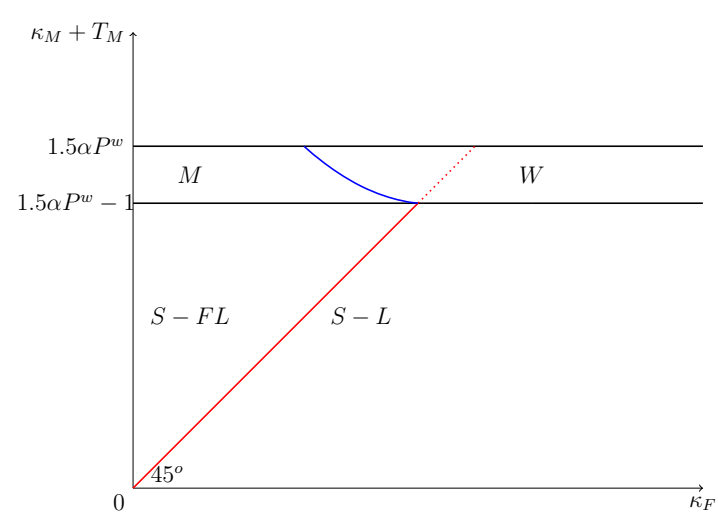

(b) A $\mathbf{5 0 \%}$ increase in $\alpha$ or $P^{W}$

Figure 5: Effect of a $50 \%$ increase in $\alpha$ or a $50 \%$ in $P^{w}$ on the equilibria types with local markets. 


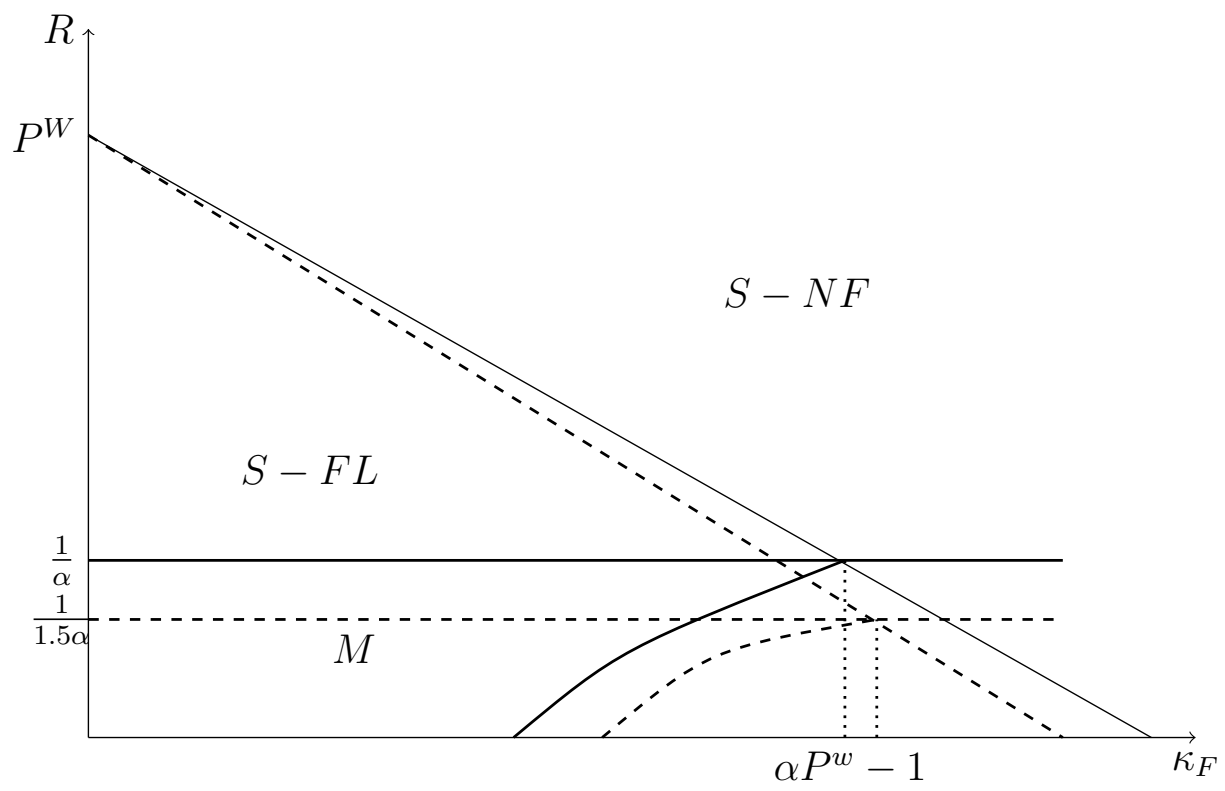

Figure 6: Effect of a $50 \%$ increase in $\alpha$ on the equilibrium types without local markets. 